\title{
Abrir la política urbana y las identidades sociales. Ni empresarios, ni burócratas, ni vecinos: estatalidad profunda y estatalidad extensa
}

\section{Opening up urban policy and social identities: Neither entrepreneurs, nor bureaucrats, or neighbours: deep statality and extense statality}

ANA N UÑEZ*

\begin{abstract}
The analysis presented in this article has its origins on the question of what social relationships get hidden, constructed and destroyed in the struggle for the material and social conditions of existence. This triggers the usage of traditional categories of urban policy that have been thought of as objects (as state, enterprises, neighbours) interrelating the construction of several social spaces that we call deep statality and extense statality. We consult primary and secondary information sources which refer to struggles for and with water and the sanitation of M ar del Plata, Argentina.
\end{abstract}

Keywords urban genesis, social struggle, deep statality, extense statality, urban policy.

\begin{abstract}
Resumen
El análisis que aquí se presenta parte de preguntarse qué relaciones sociales se ocultan, construyen y destruyen en la lucha por las condiciones materiales y sociales de existencia. A partir de ello se ponen en movimiento categorías tradicionales de la política urbana que han sido cosificadas (como Estado, empresas, vecinos), interrelacionando la construcción de distintas espacialidades sociales, que he denominado estatal idad profunda y estatalidad extensa. Para ello se recurre a fuentes de información primarias y secundarias referidas a las luchas por y con el agua y el saneamiento en el $\mathrm{M}$ ar del Plata, Argentina.
\end{abstract}

Palabras clave: génesis urbana, lucha social, estatalidad profunda, estatalidad extensa, política urbana.

* Universidad N acional de M ar del Plata, Argentina. Correo-e: aenunez@ mdp.edu.ar y nunezmdp@gmail.com 


\section{Introducción}

A mediados de la década de 1970, junto con la crisis del modelo de acumulación fordista, se produjo una ruptura epistemológica en los estudios urbanos, a partir de la crítica a las limitaciones del instrumental teórico-metodológico de la sociología estadounidense, y la revaloración del análisis basado en diferentes enfoques del materialismo histórico, sobre todo los provenientes de la Escuela de Sociología Francesa. ${ }^{1}$

A comienzos de la década de 1980, a la luz de esta influencia, los estudios urbanos latinoamericanos, en general, movilizaron mecanismos estructurales y de naturaleza económica para explicar la conformación de la ciudad y las políticas urbanas, ya sea asociándolos al modo de producción o al comportamiento económico de los agentes sociales ( $M$ arques y Bichir, 2001). En este marco, se identificaba un patrón espacial decreciente centro-periferia en las condiciones sociales, urbanas y en la intervención del Estado en medios de consumo social, ${ }^{2}$ proceso que, junto con el de autoproducción de viviendas, se subsumió y denominó urbanización de la pobreza. Bajo esta denominación, los estudios urbanos latinoamericanos, en general, referían (y naturalizaban) al proceso de migración campo-ciudad de los pobres rurales, quienes ocuparían suelo urbano desprovisto de servicios de infraestructura y auto construirían su vivienda, ubicando su génesis temporal en las consecuencias del modelo industrial sustitutivo (1950-1960). Esta naturalización y manera hegemónica de abordar el problema permanece hasta la actualidad y ha sido realimentada por los organismos y las agencias internacionales, como una forma de legitimar la producción y reproducción de la desigualdad. ${ }^{3}$ En otras palabras, me refiero a que esta denominación oculta un proceso social previo de confrontación y expropiación, sobre el que volveré más adelante.

Si bien a lo largo de la década de 1980 esos determinismos fueron remplazados por otros de nivel micro, basados sobre todo en los actores y los movimientos sociales (Castells, 1988), persistió, naturalizado y legitimado, un circuito socialmente cons-

\footnotetext{
${ }^{1}$ Las cuatro corrientes que confluían en dicha escuela eran: la de H enri Lefebvre, el marxismo ortodoxo, la de M ichel Foucault y el marxismo estructuralista.

2 Proceso al que Lucio Kowarick denominó expoliación urbana, de la que dice: "Esta noción contiene la idea de que el proceso expoliativo resulta de una suma de extorsiones, es decir, retirar o dejar de proveer a un grupo, categoría o clase lo que estos consideran como derechos suyos" (Kowarick, 1991: 85-86).
}

${ }^{3}$ Véase M urillo (2006). 
truido de pobre, localización informal, suelo sin servicios, barato, población no servida por el Estado, fragmentando el análisis urbano en dualidades del tipo legal/ilegal, formal/informal, tesis que continúa siendo hegemónica (Pereira, 2005).

Por el contrario, mi supuesto teórico es que esta ficción homogeneizante de sujetos desposeídos (ocupantes gratuitos/autoconstructores) construida y legitimada socialmente, es la que habilita, justamente, la acción racionalizadora y justificatoria de los aparatos del Estado. ${ }^{4}$ En palabras de Pereira (1986), la carencia de equipamiento y/o servicios básicos evidencia el enfrentamiento de las fuerzas sociales en la apropiación y valoración de la ciudad, y no la ausencia del Estado. Además, en las interpretaciones corrientes aparece reificado un determinado Estado del poder (Bourdieu, 1996), donde está ausente el análisis sobre las fuerzas que modifican las relaciones sociales que condensan esa estabilización (Louran, 1980). Porque esa emergencia es, en todo caso, la expresión de una lucha de clases como lucha política, económica y teórica (M arín, 1984, 1996). ${ }^{5}$

En el campo de la política urbana, el tema también ha quedado encerrado en una naturalización que fractura el problema en políticas (o arreglos formales) y necesidades (o arreglos informales) (Allen et al., 2005), fetichizándola como un producto de actores sociales previamente constituidos. M i crítica al plantamiento hegemónico del problema refiere a tres dimensiones interrelacionadas: 1) la visión teconburocrática que constriñe los ejes del debate a la naturalización de la escasez conduciendo la reflexión a materializar objetos; 2) la ausenica de una mirada genética y procesual; y 3) aun quienes propugnan por observar los aspectos sociopolíticos del problema, construyen la identidad social del demandante

\footnotetext{
${ }^{4}$ M e refiero no sólo a la producción académica que en la década de 1980 abordó como objeto de estudio e intervención al autoconstructor, produciendo una expropiación del saber técnico del obrero transformado y manipulado por los intelectuales (Foucault, 1992), y a la violenta erradicación de asentamientos irregulares durante los gobiernos de facto, especialmente la última dictadura militar en Argentina, sino a cómo el Estado es interiorizado, disfrazado, legitimado. En otros términos, el Estado siempre está presente, aunque se disimule allí donde la bibliografía dominante habla de su ausencia (Lourau, 1980).

${ }^{5}$ En realidad, pienso que partir del derecho es quedar entrampado, porque dentro de las ciencias jurídicas dos de los puntos más complejos son: 1) determinar cuándo se está o no frente a un derecho fundamental; y 2) la definición de cuáles derechos, en concreto, pueden ser considerados como sociales. Este difícil acuerdo conduce al regateo de su exigibilidad, tendiendo a negar a algunos derechos de tipo social su carácter de derecho fundamental (Espinosa Saldaña, 1997). En este sentido, el reconocimiento del derecho al agua como un derecho humano fundamental, de acuerdo con $\mathrm{N}$ aciones Unidas en el año 2002, no ha redundado ni garantizado la universalidad del goce de todos los ciudadanos a este bien para la vida.
} 
como adicional a la de usuario, atendiento a las múltiples dimensiones que surgen entre una y otra (Castro, 1999). Lo que se pierde de vista aquí es que por un lado, no siempre y no toda carencia material se transforma en demanda (por qué y cómo, me preguntaría) y, por otro, que la demanda y la apropiación de las respuestas a esta demanda es una de las formas en que la rutina burocrática, que descansa omnipotente e infinita sobre la propiedad parcelaria -diría M arx- diluye, fragmenta y dispersa, de esa manera, la lucha social (H olloway, 1994). La pregunta debiera reformularse, entonces, en términos de qué respuestas, a qué demandas, y de quién y dónde, en el proceso de estatalidad.

En mi opinión, se trata de desentrañar los mecanismos institucionales que operan en la construcción de lo que se debe demandar y analizar las interconexiones en las prácticas cotidianas de dominación. En síntesis, mi hipótesis es que la demanda no es un derecho ${ }^{5}$ que enuncia la ausencia de un Estado abstracto, sino una condición esencial del funcionamiento de las instituciones y su burocracia. Es decir, no hay dos mundos desarticulados (las demandas de la sociedad, y el Estado) unidos por hilos (Borges, 2006: 101).

Así, la perspectiva cambia al considerar, como dice Lourau (1980), que es el Estado el que nos analiza a partir de un enfoque que propone reflexionarlo no sólo como objeto sino como instrumento de investigación, es decir, abrirlo, transformarlo en un dispositivo de conocimiento de las fuerzas reales que operan no sólo en el control, sino en el proceso de construcción del orden social y, por tanto, de identidades sociales ${ }^{6}$ (Roze, 2003; Castro, 1999). En otras palabras, abrirlo es, desde mi perspectiva teórica, entrar en la estatalidad en su doble dimensión: 1) como proceso, en sus distintas facetas, y 2 ) en su construcción en profundidad y en extensión.

Esta operacionalización posibilita, por un Iado, devolverle a lo que se denomina Estado la dinámica que le imprimieran $\mathrm{M}$ arx y Engels, en su relación conflictiva que establece con las fuerzas sociales, entendiendo por éstas las alianzas de clases entre fracciones de clases que tienen distintos grados de unidad de clase, conceptualizándolo como un conjunto dinámico, cambiante, conflictivo, de relaciones entre clases, en una determinada sociedad, que expresan la dominación bajo formas aparentes de consenso,

${ }^{6}$ Utilizo identidad social en el sentido que le da Rebón, "como concepto para enfatizar el carácter social de una personificación, el haz de relaciones que expresa y su relación en términos de funcionalidad con el orden social en el que se encuentra inmerso" (2005: 18) 
y a los aparatos del Estado como la forma visible en que esta relación se materializa (Roze, 2003) y, por otro, introduce un riguroso criterio de periodización para investigaciones que abordan la historicidad de procesos sociales.

Para Castro (1999) hay un aspecto que requiere mayor atención y es el que refiere a las instituciones que detentan el monopolio estatal de los medios de la violencia legítima (Weber, 1992; Elias, 1982) y, agrego, también simbólica (Bourdieu, 1996). Empero, esas instituciones se deben leer como construidas por fuerzas sociales para librar las confrontaciones de las clases dominantes; instituciones políticas e instituciones sociales, como ámbitos del régimen, es decir, de los defensores del orden social y jurídico institucional (M arín, s/f; Roze, 2003), mediante el interjuego por el cual se intenta mantener el dominio de los intereses de una clase sobre el conjunto. ${ }^{7}$

Las formas en que se organizan estos intereses sociales y económicos particulares desde la dominación capitalista, se pueden comprender mejor a través de $\mathrm{M}$ arx, cuando esclarece las relaciones entre burocracia y corporación, dialéctica que se va a explicar como una transfiguración de los intereses, en particular, y en general:

Las corporaciones son el materialismo de la burocracia y la burocracia el espiritualismo de las corporaciones. La corporación es la burocracia de la sociedad civil; la burocracia es la corporación del Estado. [... ]

La burocracia [...] es la "conciencia del Estado", la "voluntad del Estado", el "poder del Estado" [...]. La burocracia es el círculo del que nadie puede escaparse [...]. Pero en el propio seno de la burocracia, el espiritualismo se hace un materialismo sórdido, se transforma en el materialismo de la obediencia pasiva ( $M$ arx, 1968: 59-61).

En esta crítica, la burocracia, como institución de obediencia pasiva, sería una forma de incapacidad para la lucha. Y si lo ponemos en relación con Weber: “El Estado [...] es una relación de dominio de hombres sobre hombres basada en el medio de la coacción legítima (es decir, considerada legítima)" y "El tipo más puro de dominación legal es aquél que se ejerce por medio de un cuadro administrativo burocrático. Rige el principio administrativo de atenerse al expediente" (1992: 1057-1175).

${ }^{7}$ El gobierno es el uso de esos mecanismos institucionales, en el que compiten los partidos que expresan, alternativamente, las fuerzas orgánicas propias del capitalismo. En Izaguirre y Aristizábal (2002), “El gobierno del Estado moderno no es más que una junta que administra los negocios comunes de toda la clase burguesa" ( $M$ arx y Engels, 1848). 
En síntesis, recuperando las sugerencias teóricas de los clásicos, sumadas a las de Lourau y M arín, este texto hace observable la estatalidad, en profundidad y en extensión, como proceso y en sus distintas facetas, en la configuración y reconfiguración de las relaciones sociales; las expresiones y acciones propias de diferentes fracciones sociales, cómo surgen y se transfiguran personificaciones, desafiando conceptos que aíslan Estado, corporaciones, universidad, sindicato, vecinos, etc., haciendo presente ese "entramado de interdependencias constituido por individuos" (Elias, 1982: 16), y desnaturalizando la visión dominante de que hay una ciudad que se expande y servicios escasos que, corriendo detrás, nunca llegan. En este marco, mi pregunta rectora es qué relaciones se ocultan, se construyen y destruyen, detrás del fetichismo de los objetos.

\section{Configuración de territorialidades sociales}

\subsection{Génesis urbana y de las fracciones sociales}

Parafraseando a M arx (1965: 573 y ss.), la acumulación originaria del pueblo $\mathrm{M}$ ar del Plata estuvo signada por procesos de violencia y expropiación, como fundamento del surgimiento y reproducción de las relaciones de propiedad. En otras palabras, se trata de trazar la trayectoria de los procesos histórico-sociales de confrontación en la configuración de territorios, entendidos como "ámbitos de la producción de condiciones materiales y sociales de existencia, de producción de relaciones sociales. Todo ámbito de esta naturaleza [... ] presupone un proceso de apropiación y otro de expropiación (M arín, 1996: 189).

El contexto histórico de la génesis del pueblo como saladero se ubica en pleno auge de la Argentina en la división internacional del trabajo como país agroexportador, comportando diversas transformaciones en la división social y territorial del trabajo; bajo la dominación oligárquica. ${ }^{8}$ La tierra es, aquí, el instrumento de producción de las condiciones materiales y sociales de existencia.

Sin embargo, a raíz de la epidemia de cólera y fiebre amarilla, la legislatura de la provincia de Buenos Aires cierra, a partir de

\footnotetext{
${ }^{8}$ Coincido con Ansaldi (1992) que la oligarquía es una categoría histórica y sociopolítica que designa una forma de ejercicio de la dominación de clase, caracterizada por la exclusión de la mayoría de la sociedad y puede ser ejercida por clases, fracciones 0 grupos sociales.
} 
1871, la actividad de los saladeros. La alternativa sería, entonces, subdividir la tierra e instalar un poblado, es decir, convertir tierra rural en suelo urbano. Esta decisión provoca un conflicto interburgués con otros hacendados de poblados cercanos por la alta valoración que tomarían las tierras y porque la formación del pueblo requeriría, entonces, una expropiación. Una expropiación al expropiador por parte del gobierno provincial, dado que la Ley de Ejidos prohibía la formación de pueblos sobre tierras privadas. ${ }^{9} \mathrm{~N}$ o obstante, en noviembre de 1873 se solicita la legalidad del trazado al gobierno, pero en los libros del juzgado no aparece ninguna referencia a la fundación de $\mathrm{M}$ ar del Plata, pretendidamente hecha el 10 de febrero de 1874, momento en que el núcleo del antiguo saladero era abandono y desolación (Zuppa, 1997).

En plena edad de oro del régimen oligárquico, esta consolidación por decreto de una situación de hecho, expresa un tipo de relación interregional; una forma de articulación del poder central con los poderes locales, en el marco de una redefinición social y geográfica de la dominación. ${ }^{10}$

De todas maneras, el pueblo $\mathrm{M}$ ar del Plata surge, así, promediando la década de 1870, como un loteo privado aprobado por excepción, transgrediendo la ley. Una ilegalidad fundante de las condiciones jurídicas de existencia de la tierra urbana como mercancía y del ejercicio del derecho de exclusión que otorga la propiedad (N úñez, 2008).

En 1883, cuando la ciudad de Buenos Aires era azotada por la segunda epidemia de cólera, $\mathrm{M}$ ar del Plata aparece como la opción de huida ante el peligro de muerte, entrando en conflicto la emergencia científica del saludable clima marítimo ${ }^{11}$ y el proyecto portuario que estaba en discusión, pero que tomaría fuerza de ley en 1909. ${ }^{12}$ Esta incipiente mirada al mar como un nuevo ins-

${ }^{9}$ En ese momento, toda la superficie del que sería el ejido del pueblo, pertenecía a un solo propietario: P. Peralta Ramos.

${ }^{10}$ Cómo entender, si no, que Peralta Ramos expropia las tierras de su socio, incurriendo en una figura punible tipificada en el código penal, que nunca se esclareció. ¿Intercambios pacíficos de protección o favores en un momento crucial de la conciliación? Es posible pensar a Peralta Ramos como un sujeto del régimen que busca retirarse desde una perspectiva crítica, actitud propia de un asceta.

${ }^{11}$ Así lo atestiguan varias publicaciones de la época, lo que dará origen a la construcción del Asilo M arítimo en M ar del Plata, por la Sociedad de Beneficencia de Capital Federal.

12 Los primeros proyectos concretos datan de 1887. El 30 de septiembre de 1905 se sanciona la Ley 4917, que será modificada por la Ley 6499, del 25 de septiembre de 1909, por acción del diputado Pedro Luro, transformando la localización del puerto. Este traslado del puerto al sur implicó la expulsión violenta de los pescadores del área 
trumento que transformaría el rol de la ciudad en la división nacional del trabajo, signó el predominio histórico de la lógica del capital comercial. En efecto, ya en 1881, del total del capital urbano invertido, 92\% correspondía al comercial (básicamente, tiendas) y sólo $8 \%$ al industrial ( $\mathrm{N}$ úñez, 2000). A comienzos del siglo $x x$, con el dinamismo que adquiría el mercado laboral, se produce la recepción de inmigrantes extranjeros, ${ }_{13}^{13}$ anarquistas y socialistas, imbuidos de un ideario de libertad e igualdad y esperanza de transformación social radical.

Por ende, la representación del puerto, en relación con la inmigración, se asociaba a las epidemias físicas y también morales (M urillo et al., 2005), cuyo espacio social había que controlar o neutralizar, ${ }^{14}$ acompañando la progresiva diversificación y estacionalidad del mercado de trabajo: agricultores pero también peones en hornos de ladrillos; al bañiles en invierno pero mozos en verano; pescadores y vendedores ambulantes, entre otros.

Por un lado, esta movilidad en los oficios del momento (comercio, construcción y pesca) se alimentaba de su transmisión en los gremios, ${ }^{15}$ una organización sindical por oficio o rama, constituidas para reivindicaciones concretas y como ámbitos de aprendizaje. Constituyó uno de los canales que atenuó la exclusión pero que, a la vez, facilitaba su integración al sistema, ocultando la dominación (Colombo, 1993). Por otro, esta fuerza de trabajo, dispersa, no sólo libre sino derrotada, expropiada de su territorio social, debía ser sujetada para posibilitar su consumo productivo. Así, los capitales inmobiliario y comercial comienzan a organizarse para ordenar los cuerpos y las cosas en el territorio urbano.

central de la ciudad, y la desobediencia de los informes técnicos sobre la inapropiada localización. Asimismo, Pedro Luro loteó 66 ha en las proximidades del puerto, en 1910, promocionando un barrio obrero para los trabajadores de la pesca.

${ }^{13}$ Entre 1895 y 1914, la tasa anual de crecimiento de la población extranjera en $\mathrm{M}$ ar del Plata fue superior a $72 \%$, mientras que la del país en su conjunto fue de $40 \%$ (N úñez, 2000).

${ }^{14}$ En M ar del Plata surge, en 1881, la Sociedad de Socorro de los Pobres y se decide fomentar la creación de comisiones de vecinos que colaboren con la inspección, denuncia, limpieza, control e higiene. Esta organización normativa se acompaña de una primera organización material, la división del Partido de Gral. Pueyrredón (PGP) en cinco cuarteles ( 0 rd. del 24 de febrero de 1892) y, al mismo tiempo, otra división de carácter higienista en tres secciones, en cada una de las cuales se nombra una comisión de vecinos que elegirán un presidente y un secretario ( 0 rd. del 28 de febrero de 1899). Asimismo, desde 1902 rige la Ley de Residencia $\mathrm{N} \cong 4144$, por la que podían ser deportados a su país de origen los extranjeros que perturbaran el orden social.

${ }^{15}$ En 1903 se crea el gremio de carpinteros y ebanistas; de mozos y cocineros (La M arplatense); en 1904 el Círculo de Obreros Católicos y en 1906, la Federación O brera Local, liderada por anarquistas. 
Pero si en la primera generación familiar oligárquica la acumulación de tierras era el instrumento que organizaba el poder social, económico y político (un fin), para la segunda generación será fuente de renta (un medio), un instrumento de violencia simbólica y material que franquea la aparición de distintas formas e identidades con las que se configura y despliega la propiedad en el régimen de dominación, en un momento en que se exacerba la contradicción de un proceso excluyente:

Para las oligarquías en el poder, las ciudades presentaban una fisonomía contradictoria: por un lado, eran el espejo del progreso, la modernidad, la civilización y, por otro, un ámbito de creciente hostilidad cuando (como contracara de esos mismos procesos) contingentes de obreros socialistas y anarquistas se apropiaron de esos lugares singulares. La ciudad se transformó en un lugar para el ejercicio de la protesta, el encuentro [...]. Esta "publicidad" aparecía transgrediendo la "privacidad" restringida a los clubes de notables y los círculos familiares (Funes, 1992).

Entonces, ¿cómo resolver esa contradicción? ¿Cómo defender ese territorio? ¿Cómo ejercer la exclusión de este espacio urbano que se representaba hegemónicamente como objeto privado de una fracción social dominante pero que, a la vez, se concebía como fuente de renta? Creando la periferización, ${ }^{16}$ inventando barrios en suelos rocosos, bajos, inundables, inexplotados por el capital, para espacializar y ordenar esa fuerza social de oposición.

La normatización del mercado de suelo urbano, en la articulación de los capitales comercial e inmobiliario, significó un instrumento de violencia legítima y simbólica en tanto que dependió de unos pocos terratenientes qué, cómo, cuánto, dónde y para quién lotear. Disciplina, sujeción y violencia naturalizada a partir de la ideología socialmente niveladora de la propiedad privada (N úñez, 2008). El desarrollo progresivo de la urbanización fue el ejercicio de ese monopolio, operando sucesivos desplazamientos de aquella periferia, creando barrios en el vacío ${ }^{17}$ para espacializar y ordenar los contingentes migratorios en edad activa, con sus hábitos de solidaridad y justicia social.

H acia 1900, 40\% de la población que habitaba el pueblo era extranjera; es el momento en que surge, también, el problema de la vivienda, cuya solución adoptará la forma transitoria o perma-

${ }^{16}$ Defino periferización como un proceso social de invención inmobiliaria y, por tanto, periferia como una relación social, móvil y cambiante.

${ }^{17} \mathrm{~N}$ unca un fenómeno se produce en el vacío (Elias, 1982). 
nente de conventillo para obreros y empleados; o de viviendas muy precarias de barro, madera y zinc, en los barrios:

En ese solar había una pieza que el propietario alquilaba. Una de las piezas estaba ocupada por mi abuelo, que esperaba la llegada de Italia de su mujer y su hijo. O tra de las piezas la ocupaba don Vicente, emprendedor y con un oficio, que compró un lote y entusiasmó a su compañero de inquilinato, peón rural y changador [...]. Construyeron sus casas y siguieron viviendo en proximidad. ${ }^{18}$

Alquilamos una pieza en un conventillo. Tenía alrededor de 120 14 piezas, casi todas ocupadas por gente de trabajo, obreros y empleados, aunque también en los meses de verano se alojaban turistas pobres (Woollands, 1999: 33).

En 1888, Brown y Los Andes fue el epicentro del Pueblo N uevo, con el almacén de $M$ ona, $M$ artín $M$ ona. Era del mismo pueblo de mi abuelo [...]. H ay una cosa que se Ilama $\mathrm{M}$ ar del Plata, donde está $\mathrm{M}$ artín $\mathrm{M}$ ona. $\mathrm{Y}$ bueno, vamos [...]. Entonces, bueno, andá a ver a Fulano que te vende el lote. Barrio del Pueblo N uevo [...] era una isla, ubicada en medio de un mar verde. Había un grupo de casas y había un almacén que aglutinaba [...]. Estaban mis abuelos [...]. Ahí nació mi papá. Y esto era de otros herederos Peralta Ramos, que en un momento venden en block todo eso a dos personas de Buenos Aires. A partir del 88 se empieza a "poblar", eran chacras. M i abuelo que no tenía muchos recursos compró ocho manzanas, su hermano otras ocho y su hermana casada otras ocho. Era una zona inundable, esto se inundaba. Otras ocho manzanas las tenía un español cuyo hijo se casó con la hija de una hermana de mi abuelo, ¿comprende? 32 manzanas en cuatro propietarios. Cada uno con ocho manzanas (entrevista a Roberto Cova).

Al mismo tiempo, las fracciones sociales que ejercían esta violencia y coerción fueron consolidando las prácticas veraniegas a partir de la expropiación/apropiación de este territorio. Esto significó, por ejemplo, la expulsión por la fuerza policial de los trabajadores que producían y reproducían sus condiciones de existencia en el espacio costero central, y su relocalización en los barrios creados para ello: La Pescadilla y Tierra del Fuego, en suelo rocoso, inundable, sin servicios...

En otros términos, el proceso socialmente construido, y legitimado históricamente como urbanización de la pobreza, de

${ }_{18}$ Palabras de Luis N uncio Fabrizio, ex intendente de $\mathrm{M}$ ar del Plata. Se refiere a Vicente Fagnani, luego empresario local, cuya hija se casó posteriormente con su padre, Antonio Fabricio. 


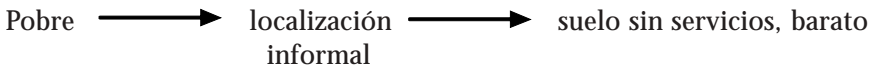

se invierte, se completa y en realidad es el siguiente: ${ }^{19}$

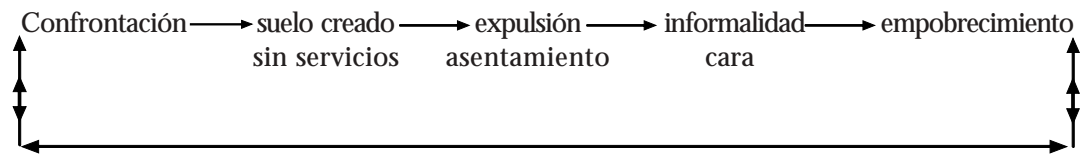

\subsection{Proceso de corporativización y ¿ciudadanización?}

Las fracciones sociales locales dominantes también se fueron agrupando para defender sus intereses corporativos. ${ }^{20}$ Así, en 1907 se crea la Sociedad de Pescadores Unidos y, posteriormente, la Cámara Comercial e Industrial. El capital ligado a la construcción funcionaba por ramas anexas (patrones de hornos ladrilleros, constructores de obras sanitarias, empresarios yeseros, etc.) que conformarán, a mediados de 1930, el Centro de Constructores y Anexos.

Este proceso de corporativización se daba en un marco en que, hasta 1916, la vida política local estaba signada por los comisionados que nombraba el gobierno provincial, proceso que se vio interrumpido sólo en tres años: 1906, 1913 y 1916. Fueron, casi todos ellos, terratenientes vinculados a los cargos y dirigentes provinciales y nacionales; pero con las modificaciones electorales introducidas por la Ley Sáenz Peña en 1912, comienzan a cambiar las prácticas, el espectro político local y los espacios de la lucha política.

El régimen de los comisionados comenzó a ser cuestionado por un movimiento social de protesta, llamado a partir de 1911 Junta Popular de Resistencia, conduciendo a los socialistas al gobierno comunal de 1920 hasta 1929, aunque no sin conflictos. La base partidaria estaba conformada netamente por fracciones

${ }^{19}$ Esta inversión del problema reconoce su origen en que "No existe inicialmente un sujeto, al que se ve, se nomina, se analiza, y finalmente sobre el que se despliegan un conjunto de acciones (de salvaguarda, de protección, de represión, de exclusión, etc.), sino que las acciones que la sociedad ejerce y los procesos de conceptualización con que se nominan, son los elementos configuradores del sujeto, resultante de esas acciones" (Roze et al., 1999: 12-13).

${ }^{20}$ Siguiendo a M arín, los intereses corporativos son "aquellos intereses que son formulados no sólo particularizando y especificando los correspondientes al sector, sino también en forma tal que pueden ser sostenidos como legítimos en relación al sistema jurídico preestablecido" (2003: 42). 
urbanas asalariadas y obreros manuales, mientras la dirigencia la ocupaba la pequeña burguesía. ${ }^{21}$

El programa electoral socialista, presentado entre 1913 y 1919, se basaba, entre otras cosas, en establecer la jornada laboral de ocho horas, aumento salarial a los empleados municipales, gravar los terrenos baldíos y ampliar obras y servicios públicos a las zonas periféricas, tendiendo a su municipalización progresiva.

Si bien estos postulados reformistas iban dirigidos a los sectores populares, la relación política con la provincia y la nación era crítica, por lo que su marco de acción se veía estrechamente limitado, como ocurrió, por ejemplo, con el proyecto de expropiación de las tierras del puerto para beneficiar a las familias asentadas. ${ }^{22}$ En efecto, diversos testimonios dicen que "abandonados por todos, hoscos y hostiles, los pobres pescadores y obreros arrastran un vivir indigno de su condición humana [...] una zona espantosamente trágica, de miseria espeluznante, que ardía en rebeldías apenas contenidas" (Cova, 1981: 7).

A este programa político local le va a hacer frente una fracción de la élite porteña y local, agrupada en la Comisión Pro M ar del Plata, que comienza su obra el 14 de febrero de 1920. El objetivo de su constitución fue, paradójicamente, la preocupación y crítica "por el abandono en el que había caído la ciudad y el balneario, librados a su propia suerte por todas las fuerzas que antes habían coadyuvado a su conservación y desenvolvimiento". ${ }^{23}$ Íntimamente ligada a otras instituciones importantes de $\mathrm{M}$ ar del Plata y Buenos Aires, ${ }^{24}$ funcionó como un gobierno paralelo de la ciudad, a la que describen como "un cuerpo con dos cabezas", logrando incluso el manejo de una partida presupuestaria de la provincia de Buenos Aires y un subsidio de la nación para realizar obras para orientar el valor de la ciudad turística.

${ }^{21}$ Teodoro Bronzini había sido mensajero, tenedor de libros y propietario de imprentas. Juan Fava, por ejemplo, era propietario de una carpintería, por lo que renunció al Ejecutivo durante una prolongada huelga de carpinteros en 1926, ambos intendentes socialistas.

22 “...sus ocupantes pagan una renta de 68 cts. anuales por metro cuadrado, lo que habla de la forma en que son explotados los habitantes de esa zona [del Puerto]. Se trata de verdaderos alquileres usurarios", Boletín M unicipal de 1929, citado en Cova (1981).

${ }^{23}$ M anifiesto del 9 de febrero de 1920, Comisión Pro M ar del Plata (1921).

${ }^{24}$ La comisión estaba formada por 71 miembros, entre los que se incluían el intendente de General Pueyrredón, los presidentes del Jockey Club de capital federal, del Club M ar del Plata, del M ar del Plata Golf Club, del O cean Club, del Yachtmen Club y del Tiro a la Paloma. Esta comisión podía sesionar tanto en $\mathrm{M}$ ar del Plata como en capital federal (Comisión Pro M ar del Plata, 1921). 
Concretamente, es un momento crucial de surgimiento de intereses que confluyen en la creación y articulación de instituciones sociales para el manejo privado de recursos públicos y que solidifique el orden social ( $N$ úñez, 2008). Es decir, comienza a hacerse presente, por un lado, la estatalidad en la dinámica del poder entre individuos, instituciones y corporaciones; en la configuración y reconfiguración de las relaciones propias de diferentes fracciones sociales y, por otro, cómo los conflictos y enfrentamientos ordenan no sólo la territorialidad social sino el conjunto de instituciones, sociales y políticas.

Sin embargo, las instituciones son procesos e instrumentos, no cosas; tienen momentos que accionan recíprocamente (Lourau, 2001). Uno, el de la universalidad, es su significado estructural (la norma, lo instituido), lo que está establecido y cuya génesis social es, necesariamente, la construcción de identidades. De acuerdo con Castro, "esas identidades no preexisten sino que deben ser construidas socialmente" (Castro, 1999: 57).

O tro momento es el de la particularidad, el significado dinámico de la institución, lo instituyente; y un tercer momento es el de la singularidad, la institucionalización, lo morfológico, las formas sociales visibles de origen estatal.

El golpe militar de 1930, el cierre de los mercados externos a la producción agropecuaria, la recesión, el desempleo y la debilidad de las organizaciones sindicales son procesos de la determinación del capital que enmarcan el inicio del modelo de acumulación apoyado en la sustitución de importaciones, que llevó a la transferencia de ingresos del sector agrícola al industrial. ${ }^{25}$

El primer periodo sustitutivo se caracterizó por una composición del capital estable, es decir, incrementos proporcionales de capital constante y capital variable, lo que significó una permanente incorporación de fuerza de trabajo al proceso productivo, debido al liderazgo asumido por las industrias ligeras. El costo de esta confrontación fue la derrota y la expulsión de gran parte de la fuerza de trabajo rural hacia los centros urbanos.

En el segundo periodo de este modelo de acumulación se alteraron las formas de organización social del trabajo al elevarse la composición orgánica del capital, es decir, comienza un proceso de industrialización basado en el reemplazo de mano de obra por capital, lo que supone la transformación en el desarrollo de

${ }^{25}$ Esta estrategia de acumulación, por supuesto, comportó una nueva alianza entre fracciones de clase, es decir, una nueva faceta de la estatalidad. 
las fuerzas productivas del país, una nueva alianza de clases y nuevas migraciones.

$\mathrm{M}$ ar del Plata participó de este complejo proceso, con una determinada característica de la distribución entre beneficios y salarios, convirtiéndose así en una ciudad apropiada para la transferencia y reproducción del excedente en los servicios, orientado a la inversión especulativa en tierra y construcción, actividad que se constituyó en importante sector de acumulación y de atracción de fuerza de trabajo.

En efecto, luego de la confusa destitución del socialismo, se reasume el conservadurismo, aunque de nuevo tinte, el manejo de los asuntos públicos en la ciudad, en alianza con las fracciones sociales ligadas al capital comercial y la construcción. Esta tregua conservadora (en el sentido de doble juego de inserción/ exclusión) parecía cobijar -bajo la destrucción/construcción, la expropiación/apropiación del espacio y la heterogeneidad de las fracciones sociales involucradas- un cierto consenso pasivo que posibilitaba el intercambio generalizado de intereses ( $M$ arín, s/f), de transfiguración de los intereses.

En otras palabras, estas transformaciones operaban en un orden de doble dimensión, modernizante y excluyente pero, a la vez, actuaban como reactivadoras de la economía y del mercado de trabajo, provocando y absorbiendo -en un interjuego- aquella movilidad geográfica y social de la población expulsada del campo. Una movilidad de nueva forma y contenido que la de décadas anteriores y un mercado de trabajo que se dinamiza por los servicios, por el mercado interno y la construcción, y se consolida de manera estacional. ${ }^{26}$

Así, por un lado, $60 \%$ de los migrantes provenía de partidos vecinos de origen agropecuario; de una zona rural expulsora con una fuerza de trabajo que emprende un desplazamiento transversal y geográfico, pero a la vez laboral (N úñez, 2000). Por otro, estas mismas circunstancias configuraron otras redes sociales que transformaron, no lineal, ni homogénea, ni inmediatamente a al-

\footnotetext{
${ }^{26}$ En invierno era el pico de la construcción, donde se invertía la acumulación del verano; en primavera se intensificaba la pesca de anchoíta y en verano los servicios (comercio, hotelería, gastronomía).

Los salarios, aunque reconocidos insuficientes por el propio Departamento N acional de Trabajo en 1933, eran, en M ar del Plata, los más altos de la Provincia de Buenos Aires y relativamente superiores al país, en general. Ver Pastoriza (1993).
} 
gunos de los aprendices de constructores en empresarios de la construcción, que a su vez formaban a otros: ${ }^{27}$

M i empresa tiene casi 60 años. La inició mi papá como empresa familiar. Desde que era chiquito lo ayudaba a hacer ciertas cuestiones [...] trabajar también en verano, por ejemplo, pero, en realidad, yo no tengo una formación de colegio industrial. Yo hice comercial. Soy arquitecto, pero lo que conocía previo a la facultad en temas técnicos tiene que ver con lo que hacía en la obra, con ayudarlo a mi viejo a hacer ciertas cosas, a ayudarlo en los veranos... (entrevista con Andrés Sanmartano).

Los D azeo llegan a M ar del Plata en 1911, desde Italia. N icolás, el tercero de los hijos, en 1940 se dedicaba al alquiler de caballos en verano, tenía una caballeriza con 80 caballos Ilamada "La Paloma", y en invierno trabajaba de albañil. Tomaba clases particulares con un ingeniero y luego rindió un examen en la municipalidad, obteniendo el título de constructor de tercera categoría. Llegó a construir mil casitas y 200 edificios. Tenía un depósito de herramientas y materiales en 20 de septiembre y Rawson... ${ }^{28}$

H acia mediados de la década de 1930 comienza un proceso de intensa movilización que se expresa como lucha económica. ${ }^{29}$ La pequeña y mediana burguesías urbanas ligadas a la construcción, deciden corporativizarse en una única institución: el Centro de Constructores y Anexos, cuyo objetivo era mantener una postura uniforme ante los sucesivos conflictos que se iban gestando en la esfera gremial. ${ }^{30}$

Paralelamente, esos trabajadores surgen en otra dimensión de la violencia que adquiere la confrontación: la migración intraurbana. O tro desplazamiento en pos de un lugar donde producir y reproducir sus condiciones sociales y materiales de existencia.

${ }^{27}$ Cabe destacar los vínculos (parentesco, amistad, lugar de nacimiento) de los empresarios con los dirigentes o delegados obreros, lo que coadyuvó al gremio a contar con las mejores condiciones sociales y el primer convenio colectivo, firmado con el Centro de Constructores y Anexos en 1938 (Pastoriza, 1993).

${ }^{28}$ Entrevista personal a Roberto Cova. Se refiere a la empresa Dazeo H nos., una de las cinco empresas constructoras locales más importantes, disuelta hace ya varios años.

29 "La lucha económica es la lucha colectiva de los obreros contra los patronos por conseguir condiciones ventajosas de venta de fuerza de trabajo, por mejorar las condiciones de trabajo y de vida de los obreros. La lucha económica contra el gobierno es política trade-unionista, cuyo fin es la de remediar los males propios de su situación pero que todavía no acaban con esa situación, es decir, no suprimen el sometimiento del trabajo al capital" (Lenin, 2004: 86).

${ }^{30}$ Este mismo argumento será utilizado por la Cámara Comercial cuando se constituya, en 1946, como Unión del Comercio, la Industria y la Producción (UCIP). El Centro de Constructores y Anexos ingresó muy rápidamente a la Federación Argentina de la Construcción como miembro de su consejo directivo y emprendía acciones corporativas con la Asociación de Propaganda y Fomento. 
Los "pobretes", desplazados por los más pudientes, empezamos a "emigrar" hacia estas regiones semidesiertas y pagando penosamente las cuotas del terreno, emprendimos la aventura finisemanal de "Ievantar el rancho". 31

Surgió por la necesidad que tenían centenares de familias honestas y laboriosas radicadas precariamente en la ciudad, la mayoría de origen foráneo, de adquirir un terrenito, construir su "techo" para vivir esperanzadamente reproduciéndose en los hijos y brindándose generosamente a la comunidad". ${ }^{32}$

Por supuesto, estos espacios no contaban con ningún tipo de inversión pública. Estar radicado precariamente y tener que emigrar habla de una nueva expropiación pero, también, de nuevas relaciones sociales mediadas por el lote y la vivienda. Los constructores, albañiles y contratistas no sólo actuaban por encargo de obras particulares, muchas veces autogestionaban su vivienda como bien de uso (la aventura de levantar el rancho era comprar el lote, proyectar, pedir permiso y construir) pero, también, alquilaban piezas a terceros a partir de su ampliación o generaban lucrativas transacciones con sus clientes y/o autogestionaban viviendas como bien de cambio. ${ }^{33}$

O tras veces, la inversión en tierra urbana potenciaba la capacidad operativa de la empresa constructora, ofreciendo lotes en mensualidades con el compromiso de proveer los servicios básicos de infraestructura.

Pero esta movilidad reconoce la conjunción de al menos dos procesos concomitantes: 1) un nuevo volumen y estructura de capital $^{34}$ (el capital económico acumulado y el capital cultural objetivado en habilidades para la construcción) de las capas obreras que posibilitaban el acceso a la casa propia, a la propiedad; y 2) la expulsión normada de la precariedad. En efecto, el 19 de marzo de 1933 se sanciona la ordenanza municipal mediante la cual se estipula el radio urbano en el que se prohíbe toda construcción de madera, zinc y barro, radio que se amplía en 1937, ${ }^{35}$ y el 3 de agosto de este año, según el Expediente 158-0-1937, se fija el límite, otro cerco urbano, del espacio urbano escaso donde se realizarían las inversiones públicas de agua (figura ।).

\footnotetext{
${ }^{31}$ Se refiere a la zona del suroeste de la ciudad (Woollands, 1990).

32 Ibidem.

${ }_{33}$ Para las distintas estrategias de acumulación de los constructores, véase Bartolucci $(\mathrm{s} / \mathrm{f})$.

${ }^{34}$ En términos de Bourdieu (1993).

${ }^{35}$ Ordenanza General de Construcciones, Capítulo x॥ y Reglamento General de Construcciones de 1937, Capítulo xiv, Art. 92‥
} 


\section{Figura I}

Cercos urbanos, M ar del Plata, década de 1930

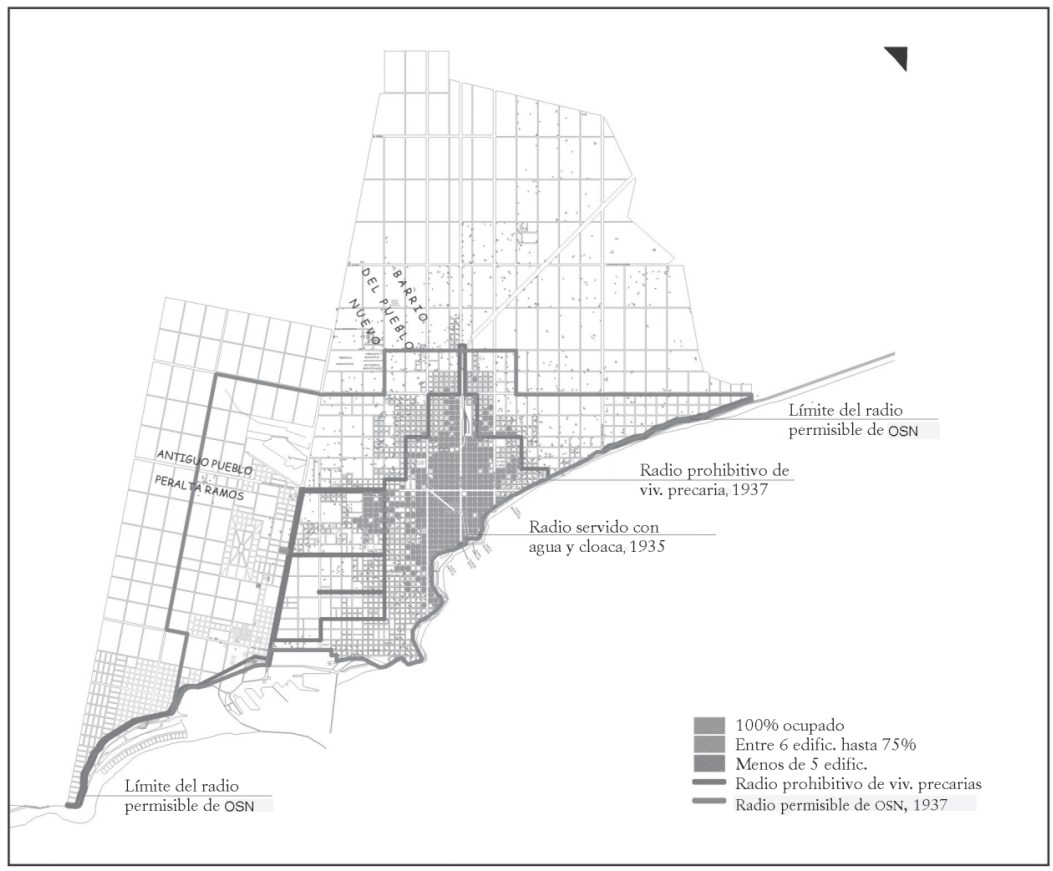

Fuente: Elaboración propia. Dibujo de Adriana Olivera.

Para entonces, $\mathrm{M}$ ar del Plata (junto con la capital federal) era una de las ciudades del mundo con mayor consumo de agua per cápita, con un promedio de entre 450 y $611 \mathrm{l} / \mathrm{h} / \mathrm{d}$. $^{36}$ Las causas que se adujeron para justificar ese el evado consumo eran tres: 1) el gran número de plazas y jardines, esmeradamente cuidados, de la ciudad balnearia; 2) las exigencias de la población turista acostumbrada al máximo confort; y 3) la fuerte presión con que se provee. ${ }^{37}$

${ }^{36}$ El estándar aceptado internacionalmente es de 100 litros por persona al día para satisfacer necesidades domésticas: bebida, preparación de alimentos y limpieza (Castro, 1999). La O rganización M undial de la Salud establece un mínimo de 150 litros por día por vivienda en las áreas urbanas de los países en desarrollo, aunque considera que 75 litros son suficientes para prevenir enfermedades.

En ese momento, había en la ciudad 17 pozos semisurgentes construidos en las cinco plazas centrales.

37 Boletín O bras Sanitarias de la Nación, año 1, 1 de julio de 1937. Este boletín apareció por primera vez en julio de 1937, por decisión del presidente de la dependencia, ingeniero Domingo Selva, por Resolución $\mathrm{N}$ N 140. Dicha resolución expresa que "en el afán de innovar y mejorar la obra inteligente y proficua que dejaron los antecesores, se precisará [... ] una mayor correlación de actividades con las demás Reparticiones del Estado [...] consiguiendo de esta manera crear estímulos para que el personal no 
En otras palabras, la exclusión y la precariedad se universalizan y se normatizan. Porque aún en 1937, los "2,000 habitantes del puerto viven hacinados, en malísimas viviendas de madera 0 chapa y en pésimas condiciones de salud e higiene, carecen totalmente de servicios sanitarios, de resultas de lo cual se instalan dos surtidores públicos". ${ }^{38}$ Sin embargo, en 1933 habían sido terminadas las obras de ampliación de provisión de agua potable en las zonas militar y comercial del puerto.

El derecho al agua parecía terminar donde empezaba el cercamiento que, como todo límite, es también una relación social; un espacio controlado, y de control, para la demanda. Considerar este cerco y su desobediencia civil como el punto de partida de un proceso social de resistencia a la exclusión, organizando distintas estrategias de apropiación del agua, comporta la imagen inversa que naturaliza un proceso en que la población aumenta, la ciudad se expande y el servicio escaso que, corriendo detrás, nunca alcanza. Pero además, ese cierre urbano que crea escasez, esa acción política de inversión pública se legitima discursivamente ejerciendo una nueva forma de violencia y un chantaje justificado en el desempleo, diciendo que

Difundir las obras públicas [...] es realizar una función técnica y social
favoreciendo una gama de gremios [...]. Los trabajos de urbanización
de Playa Grande costarán cuatro millones de pesos, que pueden finan-
ciarse con la renta. En nuestro país, poco industrializado, las clases
obreras encuentran sus medios de vida principalmente en las construc-
ciones. De ahí la importancia que tiene para el bienestar general fo-
mentar y mantener esta actividad, pues así se mantiene la capacidad de
compra de la masa de consumidores". ${ }^{39}$

En concreto, toda esta producción de instrumentos normativos de control no sólo establecía la legitimidad de las inversiones, sino lo ajeno de un espacio social escaso. Así, la acción racionalizadora de la estatalidad instauraba relaciones sociales de resistencia y desobediencia a la exclusión, pero, a la vez, creaba población cautiva que será clasificada y homogeneizada, entre otras nominaciones y en otra faceta de la estatalidad, como clandestina.

se limite a ser un mecanismo dedicado a cumplir órdenes y reglamentos, sino también a sugerir iniciativas, realizar estudios e investigaciones personales y colaborar con conciencia sin rehuir su responsabilidad. Se concibe como un órgano de discusión científica sobre los asuntos que interesan directamente a la salubridad del país".

38 Informe del ex intendente Camusso sobre la situación de la vivienda en $\mathrm{M}$ ar del Plata. En 1937, la cantidad de habitantes del puerto ascendía a más de 2,500.

39 Palabras del gobernador M anuel Fresco (Gandolfi, 1996: 68). 
Establecer material y legalmente la defensa de ese espacio social era comenzar la confrontación, dentro del campo de lucha, donde distintas racionalidades disputaban la interpretación y apropiación del espacio urbano y, por tanto, de las necesidades sociales de reproducción. 0 , en otros términos, el destino de los recursos públicos.

¿Cómo legitimar, neutralizar o canalizar esa confrontación? Para ello, era necesario tornar socialmente visible la norma establecida; era el momento de la singularidad de la institución, para redefinir el territorio social de transformación de la carencia en demanda, ya no sólo en el ámbito laboral sino también en el del barrio. Diluir, dispersar, fragmentar la fuerza social que se consolidaba en defensa de sus condiciones de existencia, incorporando al trabajador, el vecino, el sindicato a la sociedad de fomento.

Así, en el ámbito provincial, en abril de 1936, el gobernador Fresco promulga el decreto de la C édula Policial de Vecindad, de uso obligatorio para todos los mayores de 14 años $^{40}$ y, en el ámbito municipal, el gobierno establece un marco legal para la modalidad del vínculo, imponiendo la posesión de un determinado capital cultural sancionando la ordenanza titulada "Cooperación vecinal, Comisiones de Fomento", ${ }^{41}$ que será reemplazada en 1942 por la $\mathrm{N} \cong 314,{ }^{42}$ creando instituciones sociales controladas políticamente y burocratizando la obediencia pasiva a través del expediente: las Asociaciones Vecinales de Fomento (AVF).

Con la construcción identitaria del vecino legítimo y esta forma social que lo contiene, se consolida institucionalmente el canal de las demandas como un instrumento del estado del poder para legitimar la dominación y librar la confrontación, poniendo en práctica una violencia simbólica y, por tanto, socialmente acep-

${ }^{40}$ Cuarenta y ocho horas de residencia en un lugar constituían el domicilio real, de acuerdo con la Ley de Asentamientos de 1662, sobre el domicilio legal de la gente, restringiendo su movilidad al máximo.

${ }^{41} \mathrm{El}$ antecedente habría sido un decreto del gobernador Federico M artínez de H oz, de 1932, donde instaba a los gobiernos municipales para que conminasen a los vecinos a realizar obras ornamentales y de higiene en las fincas urbanas, como forma de paliar la desocupación obrera.

42 La O rdenanza $N$ ㅇ 314, que es la que se encuentra vigente, establece los objetivos y condiciones para la formación de Asociaciones Vecinales de Fomento. Dentro de los primeros se destacan las responsabilidades de velar por el mejoramiento edilicio y el cumplimiento de las ordenanzas municipales, dentro de la jurisdicción asignada, denunciando las deficiencias que se constaten. Debían contar con un mínimo de 100 socios y un radio de acción de al menos 30 manzanas; era necesario aceptar la fiscalización de la municipalidad y llevar libros rubricados; se prohibía agruparse en ligas o federaciones y hacer manifestaciones de orden político, entre otras órdenes. 
table, y velada bajo la apariencia fetichizada de una respuesta a las necesidades sociales. ${ }^{43}$

Este marco legal requiere la posesión de cierto tipo de capital para asociarse (cultural, simbólico), institucionaliza una forma social, una forma de acción y un comportamiento político. Se codifica la modalidad de ingreso y una identidad dentro de un sistema simbólico (vecinalista, fomentista, dirigente). Este ordenamiento es lo que instituye una ruptura entre lo que se puede y no se puede hacer dentro de esa forma social; donde la integración y la participación - dentro de ese sistema establecido- facilita la aceptación de la ideología dominante, pero lo que se organiza, en realidad, es un fragmento de la clasificación social: las carencias, para transformarse en demandas, no sólo deben ordenarse, justificarse y legitimarse sino que, además, deben emanar de una multiplicidad de fragmentos espaciales organizados administrativa, jurídica y materialmente, que tienen un carácter específico producido por su finalidad oficial negada, que actúa simbólicamente: se participa imaginariamente del poder pero se está excluido del control y la decisión (Lourau, 1980, 2001). ${ }^{44}$

Esta fragmentación oficial del espacio y del poder es el momento de la singularidad de la institución, el momento en que se tornan visibles formas sociales de origen estatal: "El mecanismo que pone en funcionamiento el contrato es simple: la Avf plantea al municipio la necesidad existente [...] y la municipalidad limita las solicitudes vecinales hasta el nivel que corresponde a sus atribuciones". ${ }^{45}$

En otras palabras, se decreta el nacimiento del campo barrial en coexistencia con una disputa por el campo político local, se constituyen nuevas relaciones sociales y se vulneran algunas que ya existen, se transforman las prácticas sociales. "La AVf era un espacio de trabajo para determinadas cuestiones puntuales, pero no para una proyección de barrio, quienes más participaban fun-

${ }^{43}$ Legitimar una dominación es dar toda la fuerza de la razón a la razón (el interés, el capital) del más fuerte. Esto supone la puesta en práctica de una violencia simbólica, violencia eufemizada y por lo mismo socialmente aceptable, que consiste en imponer significaciones, en hacer creer y en hacer ver para movilizar. La violencia simbólica, entonces, se sustenta en el poder simbólico, y por ello, circula en las luchas por el poder simbólico (Bourdieu y Wacquant, 1995).

${ }^{44}$ Los agentes que participan de esta lucha, reproduciendo la legitimidad de la fragmentación de la ciudad, si bien tienen una razón práctica, no actúan con una racionalidad instrumental en todos los casos. Es decir, que el efecto de visión y división funciona para ellos también, por lo que si bien pueden dar razón de sus estrategias ex post facto, esto no quiere decir que tengan plena racionalidad medios-fin.

${ }^{45}$ La Capital, 24 de abril de 1970. 
damentalmente eran los martilleros, los dueños de hoteles, y estaban en función de esto". ${ }^{46}$

Crear una AVF, sortear las condiciones de ingreso a este universo de órdenes y de legitimidad condicionada de demandas, presuponía una exclusión, dada la necesidad de poseer cierta cantidad de capital económico y cultural (domicilio, hacer actas, llevar libros, tener un local, etc.). "Se destacaron los inconvenientes que ocasionan las exigencias de personería jurídica a las entidades vecinales, manifestando que la obtención de dicho requisito requiere un trámite engorroso que no todas las AVF pueden completar y en muchos casos afrontar". ${ }^{47}$

Recurriendo nuevamente a M arx, "el mismo espíritu que crea en la sociedad a la corporación crea en el Estado a la burocracia" (1968: 59). Las Avf son establecimientos marcados, divididos en el tiempo y en el espacio social cuya base, como la de toda institución, es la exclusión o restricción: las modalidades de ingreso y egreso están codificadas y el contenido del concepto está simbolizado en el espacio urbano, vehiculizando el proceso de soldadización social. ${ }^{48}$

Somos peticionantes. Consejeros. Los consejeros estamos para recoger las inquietudes del respectivo sector, colaborar con las autoridades en la satisfacción de las inquietudes, esclarecer ante el vecindario el curso de los trámites y la marcha de las gestiones". ${ }^{49}$

Compartimos con el señor intendente, más que una línea política, una manera de pensar y dirigir. ${ }^{50}$

Pero esa pretendida homogeneidad espacial encierra heterogeneidad social, heterogeneidad en el reconocimiento oficial y en la captura de identidades oscilantes entre la autonomía y la heteronomía. La obediencia pasiva y la obediencia anticipada mediante la pertenencia a un espacio institucional les confiere, a las AVF, su doble carácter de espacio social controlado y de instrumento de control.

Así, la pretendida homogeneidad oficial desatará nuevas disputas por la definición de una idea de barrio legítima, que se

${ }^{46}$ Entrevista a Washington Píriz, de nacionalidad uruguaya y militante comunista, asume la dirección de la AVF Punta M ogotes en 1980.

${ }^{47}$ La Capital, 27 de abril de 1970.

48 "La construcción del soldado social supone cierto tipo de orden, la interiorización de órdenes que se prolongan en él, que constituyen las condiciones para que éste actúe como emisor de órdenes hacia otros" (M arín, 1993).

${ }^{49}$ Representante del Sector III, socialmente compuesto por la pequeña y mediana burguesías (La Capital, 19 de febrero de 1970).

${ }^{50}$ Presidente de la avf San Carlos, Banca Abierta, HCD, 23 de diciembre de 1997. 
corresponda con un habitante legítimo, con derechos para ser llamado vecino.

\section{Agua y facetas de la estatalidad}

La política general del estado del poder que expresa la alianza de clases del peronismo en Argentina (1946-1955), buscaba dinamizar la acumulación capitalista y actuar como conciliadora de los intereses de distintos sectores de clase, manifestada en varios campos. Efectivamente, todo el conjunto normativo del peronismo posibilitaba un mejoramiento de las condiciones de reproducción de la fuerza de trabajo pero que, a la vez, eran necesarias para la reproducción del capital nacional industrial. En este contexto, en el Segundo Plan Quinquenal "Ios servicios sanitarios pasaban a tener una eminente función social" (K reutzer, 1953: 206) y la Ley 14160/52 ratifica la "prohibición de concesiones del servicio y la consolidación de provisión de agua por servicios reducidos para poner al alcance de pobladores carentes de recursos ese elemento esencial para la vida y la higiene que es el agua". Entre otras disposiciones, el Decreto $\mathrm{N}$ 11877 , del 16 de julio de 1954, en su Art. 70 establecía que

Se podrá autorizar la instalación de los servicios domiciliarios en fincas fuera del radio habilitado, mediante prolongaciones internas de las cañerías instaladas en propiedades linderas, ubicadas dentro de dicho radio o que posean servicios por prolongación. También podrá autorizar la instalación de cañerías independientes con tramos emplazados en una o más propiedades linderas hasta llegar a los lugares de enlace con las instalaciones externas. Será imprescindible que los propietarios de inmuebles afectados por el trabajo presten su conformidad y se comprometan a mantener la servidumbre hasta tanto las fincas así servidas tengan instalaciones propias e independientes". ${ }^{51}$

¿Qué suponía este nuevo dispositivo que enlazaba el adentro y el afuera del cerco; excluidos con incluidos, aun dentro de ese radio? Suponía promover relaciones sociales hacia la legalidad, vinculando y transformando identidades sociales (clandestinos, excluidos, contribuyentes no usuarios) que confluyeran en la de usuario, construyendo ahora la de atravesante 0 atravesado pero, fundamentalmente, subyacía la condición de poseer capital económico y cultural, ser propietario y, sobre todo, buenos vecinos...

${ }^{51}$ En el Artículo 8o estipulaba que el pago se realizaba como si cada finca tuviera su conexión propia. 
Sin embargo, en forma paralela al proceso de expansión urbana, sucesivamente el municipio ha ido ampliando la jurisdicción de las AVF, obligándolas a incorporar sectores que en un primer momento se hallaban fuera de los límites del barrio y que no habían participado del loteo original. Estas acciones originaron que todos los barrios posean en su interior zonas segregadas socioespacialmente, por lo que surgieron estrategias que desplazan una posible identidad imputada al barrio:

Como el barrio tiene dos zonas, con distintas características de gente, distintas características edilicias, otra que no tienen corriente [...]. Entonces los terrenos ya de por sí están desvalorizados. La gente que vive al oeste, por no decir al fondo [...] La parte que da a la ruta tratás de mantenerla más o menos llamativa para que el que pase, vea que hay un barrio. Volcamos un poco más de esfuerzo ahí también. ${ }^{52}$

Pero, además, esos espacios sociales son atravesados por el radio permisible y/o el radio servido, originando conflictos en su interior por el destino de los recursos públicos y cortando las relaciones de buena vecindad (figura $॥$ ).

Con la Revolución de 1955, las fracciones sociales más reaccionarias de la burguesía arrebatan el control del aparato estatal que detentaba el peronismo y se inicia el proceso de represión a este movimiento (M arín, 2003). Argentina ingresa, en 1956, al Fondo M onetario Internacional (FMI) y al Banco Interamericano de Fomento y Reconstrucción (BIFR), con la consiguiente apertura al capital financiero internacional. En 1958, ya bajo el gobierno del doctor Arturo Frondizi, la transferencia de oSN forma parte del programa de modernización del aparato estatal de la burguesía desarrollista, y de la necesidad de divisas para implementar su política. Sin embargo, la oposición del sindicato fue contundente para lograr la remisión, momentánea, de este proyecto, ${ }^{53}$ aunque sí se le quita la autarquía. Uno de los instrumentos que corporizó el modelo de acumulación desarrollista fue la Alianza para el Progreso, generalizada para América Latina, de la que nos interesa en particular destacar su acción en el ámbito del agua y el saneamiento.

Dentro del Plan Decenal de Salud Pública de la Alianza para el Progreso, se creó en Argentina el Servicio Nacional de Agua

52 Entrevista a J. C., fomentista, las cursivas son mías.

${ }^{53}$ En esto han coincidido mis entrevistados Ó scar Pozzobón y Ó scar Romero, ambos pertenecientes a osN. Asimismo, lo reafirma Brunstein (1989) autor que, además, refiere a la fuerte oposición por parte del lobby de contratistas de la construcción, agrupados en la CAC, que veían peligrar su mercado cautivo garantizado por la existencia de OSN. 


\section{Figura II \\ Fragmentación del espacio urbano y del saneamiento, M ar del Plata, 1942-1955}

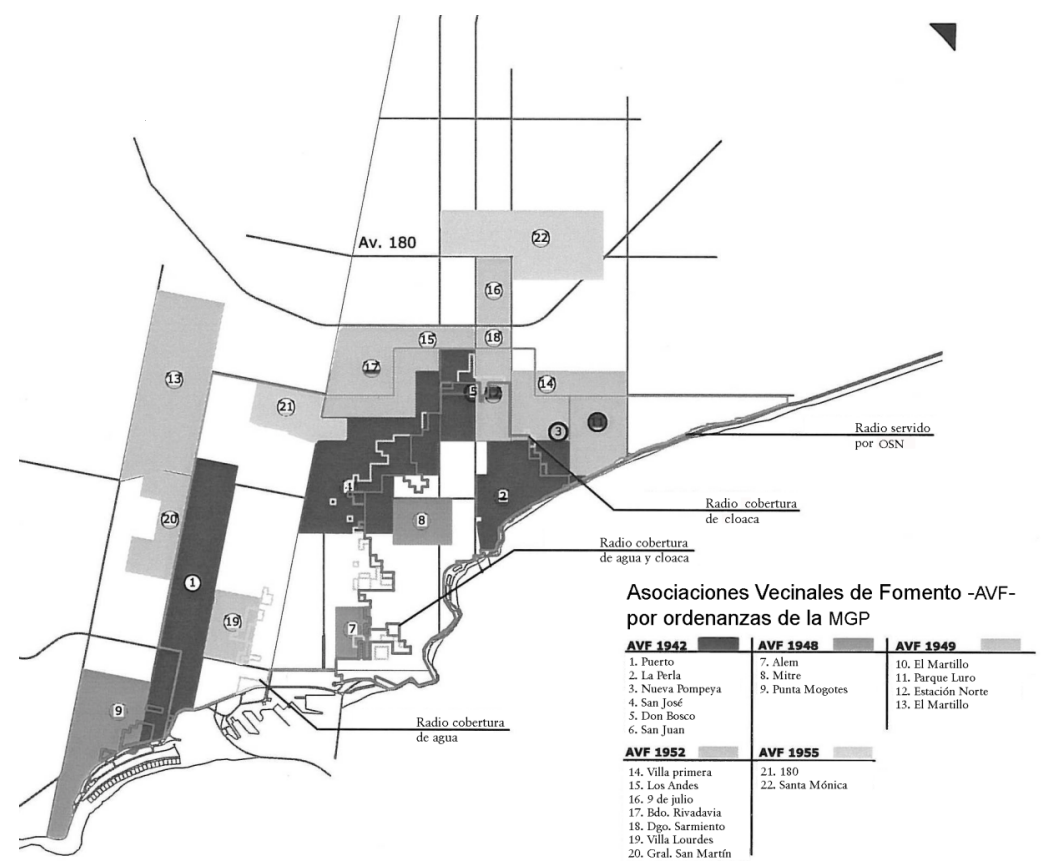

Fuente: Elaboración propia. Dibujo de Adriana Olivera.

Potable (SN AP), organismo planificador institucionalizado en 1964 por el Decreto N 09762 del Poder Ejecutivo nacional.

En 1959, el problema del agua llevó a la Organización M undial de la Salud y a técnicos de los países miembros, a realizar un primer estudio que se expresó en la Carta de la Reunión Extraordinaria del Consejo Interamericano Económico y Social, en 1961. Es allí donde se reconoce la urgencia de intensificar los esfuerzos para mejorar la salud y el bienestar social y la posibilidad de financiación parcial por organismos internacionales, con el objetivo de abastecer a $70 \%$ de la población urbana y a $50 \%$ de la rural en el decenio siguiente y reducir a la mitad las tasas de mortalidad..$^{54}$

Concretamente señalaba "darle la más alta prioridad al abastecimiento de agua y la eliminación de excretas en las zonas ur-

${ }^{54}$ Cuarenta y tres años después, en 2002, diversas cumbres internacionales acordaban reducir a la mitad el número de personas que carece de acceso al agua y al saneamiento para el 2015. 
banas y rurales de América Latina" (SNAP, 1968). ${ }^{55}$ Así, el saneamiento aparecía como otro vehículo del alineamiento político al capital financiero internacional. ${ }^{56}$ Ese compromiso se plasmó en nuestro país en la Resolución M inisterial $\mathrm{N} 0$ 1282, mediante la cual se creaba una comisión integrada por representantes de la Dirección General de Provincias del M inisterio del Interior; de la Escuela de Ingeniería Sanitaria de la Universidad de Buenos Aires, de la AGOSN, del M inisterio de Asistencia Social y Salud Pública y la O ficina Sanitaria Panamericana.

EI antecedente para la puesta en marcha de este engranaje burocrático y financiero, era la mortalidad, medida por medio de la esperanza de vida y la mortalidad infantil tardía. Esta última, a excepción de la capital federal y las provincias de $\mathrm{M}$ endoza y Santiago del Estero, alcanzaba niveles superiores a 30 0/00.

Esto llevó a implementar una prueba piloto en dos localidades argentinas, lo que dio las siguientes conclusiones: 1) que las poblaciones rurales argentinas, debidamente motivadas, se presentan accesibles al cambio de actitud frente al problema del agua; y 2) aun en el caso más desfavorable, las tasas a fijar estaban al alcance de los recursos de la población.

Pero además, las consecuencias que derivaron de esta intrusión del capital financiero internacional resultan, en mi opinión, relevantes y desmontan la creencia naturalizada que los aparatos del Estado (al menos los vinculados con el saneamiento) se transformaron para adecuarse al capital privado a fines de la década de 1980.

D os de esas consecuencias fueron: 1) que se necesitaba conocer las normas de cada constitución provincial acerca de los servicios públicos, para evaluar impedimentos o no para la entrega de los mismos a las comunidades; y 2) que una vez firmado el

55 Toda la síntesis que sigue está basada en este documento. Al mismo tiempo que se hacía esta declaración, el PEN fijaba un nuevo régimen tarifario para los servicios sanita-

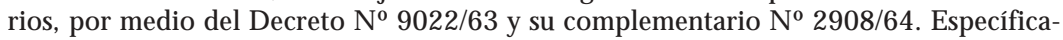
mente, las tarifas básicas mensuales se fijaban en función del capital inmobiliario y no del costo de producción y/o consumo del servicio: superficie del terreno y superficie cubierta total.

${ }^{56}$ En octubre de 1964, bajo la presidencia del doctor Illia, se firmaron dos contratos de préstamos con el BID. Sin embargo, el BID no financiaba los estudios de factibilidad previos, por lo que se analizaron dos alternativas: 1) solicitar la contribución del Fondo Especial de $\mathrm{N}$ aciones Unidas (que consistía en proveer asesores, firmas consultoras, equipos de investigación, etc.) y 2) apelar a un préstamo de tres millones de dólares, acordado en 1961 con la estadounidense Agencia para el Desarrollo Internacional (AID) para financiar estudios de factibilidad. El Banco M undial tenía destinado en Argentina un asesor que, junto con el Conade, realizaba una evaluación de las necesidades de los distintos sectores del país, para efecto de establecer prioridades. 
convenio, se procedía a los estudios preliminares para reunir información sobre el territorio de la provincia, en cuanto a detalles de disponibilidad de fuentes de agua superficiales y subterráneas, mediante investigaciones hidrogeológicas. Estas dos cartas se barajaban, en el juego financiero internacional, 30 años antes de los últimos procesos de concesión de los servicios al capital privado en Argentina.

Para concluir, el SNAP elaboró un convenio modelo que distribuyó en cada provincia argentina y que luego reajustó el BID para concretar los préstamos, a partir de lo cual cada provincia comenzó a organizar su servicio de abastecimiento rural, y el SNAP, los Cursos de Adiestramiento para Promotores de la Comunidad en cada una de ellas.

¿Cuál fue el derrotero del proceso? Se partió de la muerte como dato (instalar el miedo); la investigación concluyó en que la sociedad era maleable al cambio (heterónoma) y que podía pagar el servicio de agua (contribuyente). El miedo a la muerte, contribuir al cambio, obedecer, poder pagar, parecían, entonces, los caminos posibles para acceder al agua. Pero para el Banco M undial (BM), "una vida productiva no sólo suponía estar vivo, sino estar bien [...] si no disminuye significativamente la tasa de natalidad, habrá un crecimiento rápido de la población en el mundo en desarrollo, lo que presionará sobre los recursos naturales, sobre todo el agua, y creará problemas de contaminación" (Rovani, 1979: 15). ${ }^{57}$ La amenaza, la causa de la mortalidad era, para el capital financiero, la intensa presión del crecimiento demográfico.

A partir de la reestructuración capitalista de comienzos de la década de 1970, se produce un cambio en el crédito, a partir de un programa de investigaciones del BM, conducente a fijar normas de tarifas de agua para enfrentar tres objetivos simultáneos: 1) capacitar a los pobres para recibir niveles de servicios a precios que puedan pagar; 2) recuperar los costos de inversión; y 3) evitar el desperdicio de agua. Su justificación era que "el potencial productivo de los hogares pobres se reduce por el tiempo y energías gastadas en obtener cantidades de agua suficientes para satisfacer sus necesidades básicas" (Rovani, 1979: 15). En tal sentido, los préstamos se dirigieron a ciudades medias y pequeñas para financiar puestos de distribución, es decir, grifos públi-

${ }^{57}$ Yves Rovani fue director del Departamento de Agua y Telecomunicaciones del Servicio Central de Proyectos del Banco M undial. 
$\cos ^{58}$ y otros métodos baratos. El вM "reconoce que es una necesidad básica para todas las gentes (sic) y también, a niveles superiores de consumo, un producto primario como muchos otros en el mercado" (Rovani, 1979: 15).

En M ar del Plata, "osN invertirá 7,860 millones de pesos, todo supeditado a la demanda y posibilidad de financiación". ${ }^{59} \mathrm{~A}$ modo de ejemplo, en el cuadro 1 se pueden ver algunas de esas demandas, cuyas respuestas no sólo serán de acuerdo con la identidad imputada al fomentista, sino al cambio de dirección en la política de los organismos internacionales, para los cuales ya en la década de 1970 el agua era claramente una mercancía.

\section{C uadro 1 \\ Demandas y respuestas, $\mathrm{M}$ ar del Plata}

\begin{tabular}{lccccc}
\hline \multicolumn{1}{c}{ Barrio } & Sector & Motivo & Pedido & Respuesta & Identidad \\
\hline $\begin{array}{l}\text { Parque } \\
\text { Luro }\end{array}$ III & $\begin{array}{c}\text { Agua } \\
\text { contaminada }\end{array}$ & $\begin{array}{c}\text { Incluirse en } \\
\text { plan osn }\end{array}$ & $\begin{array}{c}\text { Promesa de } \\
\text { gestión ante IM }\end{array}$ & $\begin{array}{c}\text { Peticionantes/ } \\
\text { consejeros }\end{array}$ \\
$\begin{array}{l}\text { Juramento } \\
\text { I }\end{array}$ & $\begin{array}{c}\text { Aguatero sin } \\
\text { higiene }\end{array}$ & Agua & Trescanillas & Díscolos \\
\hline
\end{tabular}

Fuente: Elaboración propia con base en el diario La Capital, 21 y 23 de mayo de 1970.

En la fase final de la Revolución argentina, se convoca a elecciones. El peronismo, habiendo recuperado su personería electoral, llega nuevamente al gobierno nacional en 1973.

De los conflictos que se suceden entre 1973 y 1976, 28\% los protagonizan los gremios estatales y gran parte de los organismos del aparato estatal son territorio en disputa, bajo la forma de tomas (Izaguirre y Aristizábal, 2002; M arín, 2003). osn también había pasado a ser una empresa estatal (Ley 20324) y, por ende, territorio en disputa. El largo proceso de enfrentamientos, expropiación y desmantelamiento de este territorio durante la última dictadura militar (1976-1983), en un proceso de disciplinamiento social generalizado y aniquilamiento de las fuerzas populares, fue algo que permaneció ausente para la bibliografía dominante, la que consideró el momento de la privatización como un punto de partida y de llegada (N úñez, 2007).

${ }^{58} \mathrm{El}$ consumo por habitante de un grifo es inferior a $25 \mathrm{l} / \mathrm{d}$, mientras que una conexión a la vivienda es de $100 \mathrm{l} / \mathrm{d} / \mathrm{h}$.

${ }^{59}$ En diario La Capital, 14 de mayo de 1969. 
La lucha que mantuvieron los trabajadores para reapropiarse de su territorio expropiado, en el caso de M ar del Plata, desemboca en la municipalización del servicio en 1982.

\section{Entre el secreto y la lucha por abrirse camino}

En general, los estudios sobre política urbana han abordado los vínculos y las relaciones entre algunos de los involucrados como algo dado, cosificados, y con un énfasis excesivo en la corrupción y en el clientelismo, ambos en sus variadas formas, o entrampados en una oposición indisputada clientelismo vs. acción colectiva (Borges, 2006). Así, aparecen reificadas las empresas, la burocracia y los vecinos en términos de actores y escenarios, construyendo un obstáculo epistemológico. Pero, ¿qué hay en el interior y detrás de esos conceptos? ¿Cuáles son sus formas, los mecanismos y relaciones sociales que les permiten funcionar?60 Por otra parte, aun cuando el municipio ha sido el ámbito social clave de las políticas neoliberales, vehiculizando las reformas estructural es emanadas de los organismos internacional es de crédito, se ha prestado poca atención a las formas que asumen las alianzas de las fracciones sociales dominantes locales, y sus acciones en tanto fuerza política que viabilizó el programa neoliberal. ¿Qué lazos sociales y políticos articulan la estatalidad profunda (el blindaje $e^{61}$ hacia su interior), y la estatalidad extensa, su permeabilidad ${ }^{62}$ hacia y con el exterior? ¿Cómo median las obras en la construcción/destrucción de esos lazos? En palabras de M arx:

El espíritu general de la burocracia es el secreto, el misterio guardado en su seno por la jerarquía y hacia fuera, por su carácter de corporación cerrada [...]. En cuanto al burócrata tomado individualmente, la

\footnotetext{
60 Estudios recientes sobre política urbana (M arques, 2003; M arques y Bichir, 2001) desmontan fuertes hipótesis explicativas derivadas de la teoría de las élites y del pluralismo, centrándose en el neoinstitucionalismo para analizar las características constitutivas del Estado y los vínculos y relaciones que lo cercan, y su permeabilidad a las demandas de políticas por parte de las empresas. Si bien reconozco las originales aportaciones de estos trabajos, en ellos no hay suficiente lugar para los vecinos, y el sindicato, por ejemplo, en su constante resignificación. Asimismo, los resultados empíricos que presento en este acápite, me apartan de las explicaciones que sobre política urbana ofrecen las hipótesis sobre vínculo electoral y la causación circular.

${ }^{61}$ El blindaje, el cierre social, refiere a que determinados grupos sociales se apropian y reservan para sí mismos - o para otros allegados a ellos- ciertas posiciones sociales (Ansaldi, 1997; Giordano, 2003).

${ }^{62}$ Permeabilidad es una categoría analítica acuñada por M arques (2000) para denotar una cualidad ligada a una acción potencial (ser permeado).
} 
finalidad del Estado se hace su finalidad privada: es la lucha por los puestos más elevados; hay que abrirse camino [...]. El Estado no existe ya más que en forma de espíritus burocráticos diferentes y fijos, cuyo vínculo es la subordinación y la obediencia pasiva [...]. El burócrata ve en el mundo a un simple objeto de su actividad (1968: 61-62).

\subsection{La estatalidad profunda}

Los momentos iniciales de la municipalización del agua y el saneamiento se desarrollaron en un ente descentralizado del municipio (el Instituto M unicipal de Desarrollo Urbano, Imdur), homogeneizando a los trabajadores sanitaristas como empleados municipales, con el objetivo de disciplinar y unificar los conflictos, decisión tomada por el intendente y el gobernador de la provincia.

El Imdur estaba presidido por un representante de una fracción de la mediana burguesía local, quien a su vez ocupaba un cargo directivo en la ya mencionada ICIP. ${ }^{63}$ Es quien vehiculiza el ordenamiento de los cuerpos y las cosas en la reconstrucción del territorio, cuya táctica será quebrar sindical y espacialmente a los nuevos trabajadores incorporados.

En torno a esta decisión se trabaron, al menos, dos disputas: 1) entre fracciones y al interior de la mediana burguesía política burocratizada, por el control y el manejo de los recursos económicos que significaba el servicio; ${ }^{64}$ y 2 ) entre los obreros del saneamiento y una fracción de esa mediana burguesía por la pérdida de sus reivindicaciones, identidad, escalas, etcétera. ${ }^{65}$

¿Q ué atraviesa y unifica ambas disputas? Q ue se estructura en torno a un territorio vinculado a las condiciones de vida y reproducción de la población. Sin embargo, en esa mediación cada una sintetiza y personifica fracciones y relaciones que, teñidas por el dinero, hacen a la reproducción de sus condiciones de existencia: una, la apropiación de los recursos públicos; otra, la remuneración de su fuerza de trabajo. ¿Cómo dirimirlas y legitimarlas?

A lo largo de dos años ininterrumpidos (1982-1984) se desarrolló otro ciclo de luchas, en su emergencia económica, teórica

${ }^{63}$ Era la corporación empresaria de la mediana burguesía local, creada en la década de 1930. Este directivo (A. B.) era contador, empresario mosaísta y profesor de la universidad local. Entre 1970 y 1992 ocupó los cargos sucesivos de vocal, protesorero, tesorero y presidente de la ucıp y en 1975 había ingresado a la administración central de la municipalidad como Director de Compras y Suministros.

64 “En dos días nos dimos cuenta que estábamos juntando plata a rolete. Si no había inversión y había recaudación, bueno [...]. El secretario de $\mathrm{H}$ acienda quería manejar la plata, pero la plata la manejo yo" (entrevista con A. B., ex director del Imdur).

${ }^{65}$ En el ámbito local se libraba lo que se denominó guerra de los sindicatos, a la vez que había una división interna del sitos y una oposición total del gremio en todo el país. 
y política en el ámbito nacional, del que M ar del Plata era sólo una parte. Periodizar sus momentos, ${ }^{66}$ trabajando con el concepto de que se estaba construyendo un territorio nuevo, luego que había sido arrasado y expropiado el anterior; me llevó a concluir que el conflicto en realidad era una alianza entre gobierno y sindicato, y que más allá de las reivindicaciones económicas de los trabajadores, iban trasmutando sus instrumentos de lucha para defender su identidad social de sanitaristas, algo que las transformaciones económicas e ideológicas amenazaban con matar. Ellos avanzaban en la reconstrucción de un territorio expropiado; el gobierno municipal veía en la política de saneamiento, el saneamiento de las arcas municipales. Finalmente, en un contexto de pujas económicas y partidarias, aquella alianza se corporizó en una nueva institución política, O bras Sanitarias Sociedad de Estado, ${ }^{67}$ que será, nuevamente, una imbricación de resultado, proceso e instrumento de lucha social. Empero, esta disputa interburocrática librada al interior de la burguesía política, no significó que la sociedad permaneciera inmóvil, sino indefensa: el congelamiento histórico de la inversión pública, era inversamente proporcional al recorrido del aguatero, al consumo de agua contaminada y al recurrir a los escasos grifos públicos (figura III).

Para indagar en lo que he conceptualizado como estatalidad profunda, me desplazo del espíritu normal de la burocracia racional (Weber, 1992) al de las interacciones entre los cuerpos, su ordenamiento y movimiento, que hace al génesis de las relaciones y a la transformación de las instituciones para librar nuevas confrontaciones y, por ende, a la realización del poder y la reproducción del orden dominante. Parto de pensar el génesis y el movimiento de las relaciones, más que en redes, en un estado de fuerzas que estalla, en términos de Bourdieu (1993), como campo y como cuerpo. Porque entre el secreto y la lucha por abrirse camino, se despliega un sistema de estrategias de reproducción adaptativas, ${ }^{68}$ categoría dinámica y plausible de sintetizar las alianzas y confrontaciones

${ }^{66} \mathrm{H}$ ice el seguimiento diario del conflicto por medio de la prensa local, construyendo una matriz de datos con 19 variables. El desarrollo de los ciclos de lucha entre 1973 y 1984 se puede ver en $N$ úñez (2007).

${ }^{67}$ Una Sociedad de Estado es una sociedad constituida bajo las formas del derecho privado, pero cuyas acciones están totalmente en poder del Estado. El control de la empresa se realiza internamente, mediante una asamblea de accionistas que, en el caso de $\mathrm{M}$ ar del Plata, es el $\mathrm{H}$ onorable Concejo Deliberante.

${ }^{68}$ Esta categoría, construida por Leopoldo Bartolomé, permite analizar y articular la interrelación entre conductas individuales y los determinantes estructurales, aunque este autor lo refiere al proceso en que una unidad social satisface sus necesidades básicas y hace frente a las presiones del medio (Gutiérrez, 2004). 
Figura III

\section{Espacialización de las estrategias de apropiación del agua, M ar del Plata, 1980}

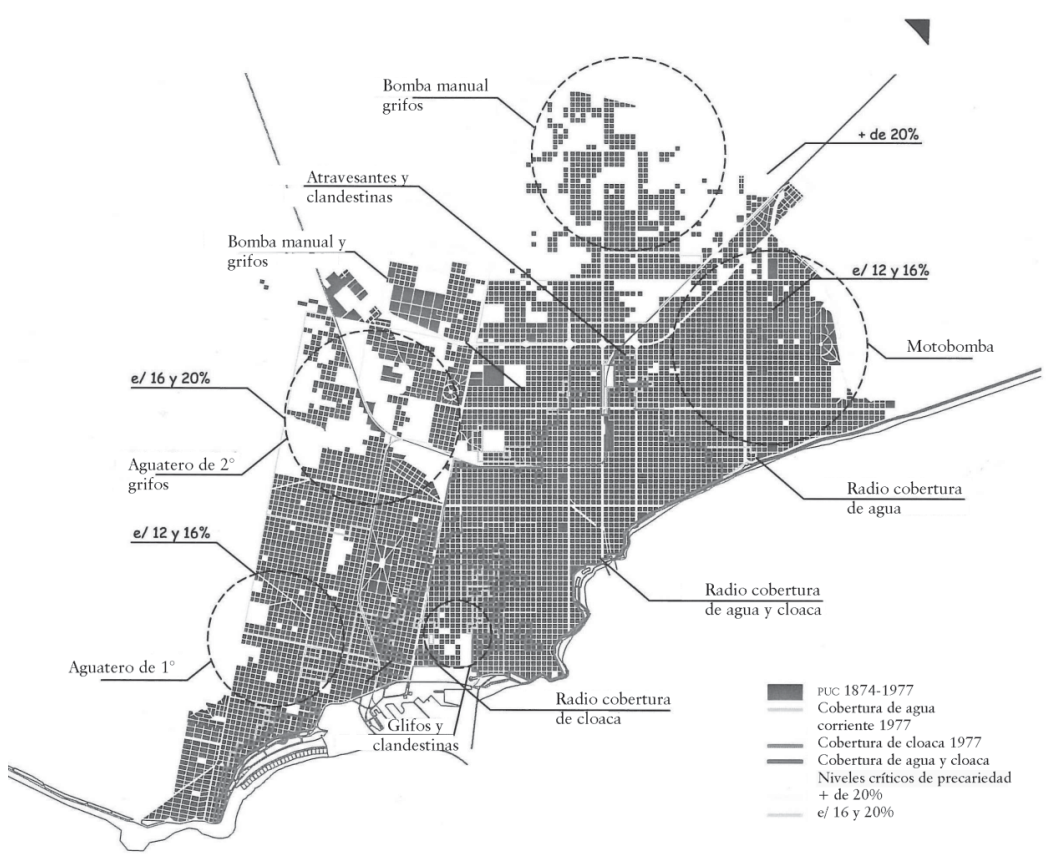

Fuente: Elaboración propia con base en entrevistas. Dibujo de Adriana Olivera.

entre los funcionarios de la clase dominante y que, además, plasma la inexistencia de fronteras institucionales (figura Iv).

¿Quién personifica esas estrategias? ¿Qué relaciones expresan, en su deambular, y cómo trasmutan las personificaciones en las distintas relaciones, pasadas, presentes y en sus apuestas futuras? ¿Cómo se transformó la institución estatal y cómo se expresó en las confrontaciones? ¿Q ué contradicciones y tensiones condensa en su interior y cómo se resuelven? ¿Cómo se articuIan los distintos ámbitos de relaciones sociales?

Los primeros momentos de la municipalización del saneamiento encuentran un ente descentralizado de escasos recursos, cohesionado y centrado en sujetos jerárquicos que personificaban, por un lado, al capital y, por otro, al saber técnico, que median entre el gobierno, los vecinos y las empresas constructoras.

Pero esa mediación, además, se alimentaba por relaciones ya establecidas, por ejemplo, en el ámbito educativo: "Patricio G her- 


\section{Figura Iv \\ Vínculos y trayectorias de funcionarios y técnicos, M ar del Plata, 1983-2002}

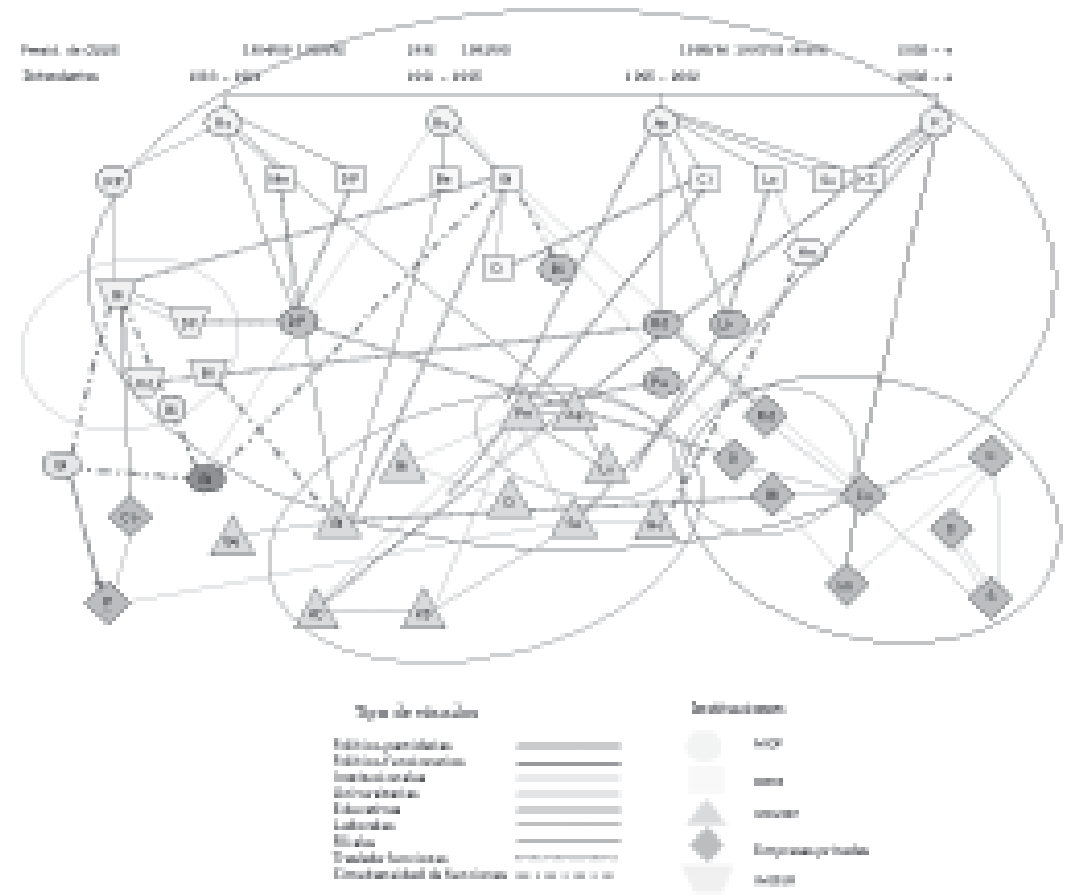

Fuente: Elaboración propia con base en entrevistas. Dibujo de Adriana Olivera. A igual letra, misma persona.

bi ${ }^{69}$ había sido alumno mío en tercer año en el Peralta Ramos. Antes, con el papá, era una empresa constructora común y silvestre..." (entrevista personal con A. B.).

Pero el poder institucional del director le otorga, a la vez, el monopolio del nombramiento, transformándolo en patrón de quien busca trabajo como sustento material. La selección aparece mediada por una relación de identificación institucional preexistente; quien necesita ayuda, personifica no sólo un saber técnico, sino una relación afectiva con un pasado educativo, que le otorga un plus para acceder al cargo: "Cuando De Pasquale toca el timbre pidiendo trabajo, en su currículum me tira que había sido alumno del Peralta Ramos. Porque en igualdad de condiciones, si vos venís del Peralta Ramos, venís vos primero. En igualdad de condiciones" (I bidem).

${ }^{69}$ Patricio Gherbi, hijo del inmigrante italiano, Ángelo G herbi, es quien está actualmente al frente de la empresa CoArCo. 
Pero el juego democrático y la alianza que generó la Sociedad de Estado reconvierte los capitales necesarios para abrirse camino y la ocupación de un puesto jerárquico pasa a ser la materialidad de una identidad producto de las prácticas heteronómicas de los partidos políticos (Roze, 2003), rompiendo e invirtiendo los lazos anteriores: "D espués, bueno, él era compañero de promoción de todos los que vinieron [...]. El día que lo llama el intendente me dice: 'Traigo buenas para mí y malas para usted. M e nombraron a mí director'" (Ibidem).

0 tras estrategias son, por un lado, la migración de un mismo funcionario entreinstituciones políticas y hacia una empresa constructora, trasladando todo su conocimiento del movimiento de las finanzas públicas; ${ }^{70}$ y, por otro, la ocupación por un mismo funcionario de dos o más cargos jerárquicos simultáneos, en distintas instituciones:

En ese momento, siendo presidente de oSSE, pedí licencia en UCIP, por un mes [...]. En ESEBA gané la elección y me nombraron en el directorio. No era incompatible con oSSE, así que me quedé un tiempo con los dos..." (entrevista con A. B.).

Ó scar Rodríguez termina de secretario de $\mathrm{H}$ acienda y pasa a gerente comercial y general de CoArCo. Es vivo. Se lo lleva para adentro. De Pasquale también trabajó. El mismo Baltar, no sé qué relación tenía pero por ahí los seducían [...]. No hablemos de actos de corrupción concreta pero hay otras maneras de seducir a la gente ¿no? (Ibidem).

En síntesis, la corrupción, que aparece aquí como colusión, es una relación de intercambio social clandestino entre el espacio público y el privado (Giordano, 2002); como un proceso de seducción, captura y migración de técnicos y funcionarios entre aparatos del Estado y hacia las empresas privadas, trasladando recursos y conocimientos, técnicos y de la administración que, una vez apropiados, se descarta el intermediario: "Si él se peleó con CoArCo por una cuestión económica [...]. No sé si De Pasquale no era tan valioso y CoArCo también tiene profesionales como material descartable, no sé... O las dos cosas, digamos..." (entrevista con A. B.).

Por otra parte, con el juego democrático se iniciaba una cooptación de los intelectuales orgánicos. La materialidad de esa co-

${ }^{70}$ El contador Ó scar Rodríguez pasa del Imdur a la Secretaría de H acienda de la municipalidad, luego a oSSE y, posteriormente, reviste como gerente comercial y general de CoArCo. Su estudio privado lo compartía con el contador Sergio Fares, quien luego lo reemplaza en la Secretaría de $\mathrm{H}$ acienda. 
optación, que borra toda frontera institucional entre municipalidad-universidad-oSSE, era el Convenio de Cooperación. ${ }^{71}$

Una suma de lealtades, reproductoras de la obediencia anticipada y subordinadas a los recursos que cada uno pone en juego. Pero, después "lo vi escondedor, no hubo reciprocidad en la lealtad. De hecho, el timorato duró cuatro meses, cinco meses cuando tuvo que firmar un acuerdo con La Florida" (De B., sobre Cionchi).

El blindaje, la organización partidaria constitutiva de la alianza construida al interior de la universidad, desplaza ahora a quien materializa el saber pero no renuncia a su identidad, trasmutando su personificación de técnico, a funcionario no capturado por ese grupo. "Querían otro tipo de gente. Querían políticos. Después viene José Luis [Cionchi], pero como no estaba en el negocio... Era un tipo muy especial, muy técnico, de muy pocas palabras, tranquilo, pero es capaz, recapaz... Estos venían a afanar y había gente que molestaba" (entrevista con O. R.).

Su desplazamiento del cargo resultaba de una lucha política pero, hacia el exterior, aparecía resuelto en el ámbito de la lucha económica, ${ }^{72}$ concluyendo en su renuncia. ${ }^{73}$

En el contexto de este conflicto, accede a la presidencia de oSSE el ingeniero M arcelo López, ${ }^{74}$ un funcionario cautivo de los ilegalismos del grupo, intermediario de la alianza universidadmunicipalidad, que lideraban el entonces rector y el intendente:

\footnotetext{
${ }^{71}$ M ediante Resolución del Directorio $\mathrm{N}$ 154/96 y ratificado por la O rdenanza $\mathrm{N}$ ㅇ 10381 se firmó un convenio entre oSSE y la Facultad de Ciencias Exactas para estudiar, en forma rentada, un sector receptor de la descarga cloacal. Ese convenio se pactaba siendo el ingeniero José Luis Cionchi presidente de oSSE (anteriormente gerente de recursos hídricos), profesor en dicha facultad y, después, decano. Asimismo, José Cionchi era gerente de oSSE cuando Bianchini ocupaba la presidencia. Pero, además, mantenían vínculos en la universidad al ser aquél decano de la Facultad de Ciencias Exactas y éste vicedecano de la Facultad de Ciencias Económicas.

72 M e refiero a un conflicto surgido en el año 1995, desencadenado por el tequilazo, respecto de la construcción de una obra de desagüe cloacal para cuatro barrios del norte, licitada en el año 1992. La obra se había adjudicado a la empresa nacional O bras y Proyectos y Construcciones Civiles, S. A., del ex diputado nacional M oisés Fontela, integrante además del grupo de legisladores peronistas que en 1989 había conformado el Grupo de los 8. Si bien el desarrollo de este conflicto sería objeto de otro trabajo, podemos decir que dado el momento y las características que la lucha había alcanzado, el Deliberativo aprueba que oSSE se haga cargo de la obra y los pagos adeudados por los vecinos a la empresa, según la O rdenanza N o 10974, en el marco del inicio de remates de propiedades a los vecinos, siendo que la obra quedaba cedida automáticamente a oSSE por ley.

${ }^{73}$ Renuncia al cargo aconsejado por su amigo, el doctor Ó scar Romero. N o obstante, posteriormente reingresa a oSSE como gerente de obras.

${ }^{74}$ Antes de entrar en OSSE, M arcelo López era secretario académico de la Facultad de Ingeniería y secretario de la producción de la municipalidad.
} 
La única manera de robar era desplazando a Cionchi y a otra gente decente, con un hecho bastante jorobado. Cionchi se va y viene la banda. Para sacarlo, hacen una reunión en la casa de Basualdo, cerca de la universidad con Petrillo, [rector] también $M$ argarita Torres, la negra, con el otro sinvergüenza que estaba en vialidad, y Aprile [intendente]. Ahí hacen todo el paquete. Ahí empieza todo. Gente que no les respondía, gente que liquidaban..." (entrevista con 0 . R.).

De este modo, la institución pasaba a ser apropiada como un instrumento de acumulación política y económica, por los cuadros de la clase dominante. El directorio, se transformaba en comunidad (Weber, 1992). Sin embargo, el inicio de este nuevo proceso requería otras relaciones que instauraran a estos funcionarios como autoridad legítima, hacia dentro y hacia fuera. Detrás de las obras, se ocultarían, impunemente, el delito económico organizado y el delito de la irresponsabilidad (N úñez, 2006).

\subsection{La estatalidad extensa}

La empresa constructora local, mayormente vinculada al gobierno, era CoArCo, que se inició en la obra pública en 1982, a partir de la gran expansión de las obras de gas en la ciudad. Sin embargo, como señalé antes, los vínculos entre el gobierno y la empresa se daban en otros ámbitos sociales.

La otra empresa marplatense, con escasa capacidad primigenia de acumulación, tanto técnica como financiera para aspirar a hacer obra pública, era Imepho, cuyos orígenes en tipo y volumen de capital, comparte con Dazeo y Sanmartano, ya descritos en al acápite 1.2.75 El escaso capital objetivado en obras impedía a estas empresas aspirar a las licitaciones de saneamiento. Así, antes que el lobby, fue la ayuda del gobierno a las estrategias de acumulación empresarial lo que explica el lento desarrollo espacial y temporal de las obras de saneamiento: “En la época mía se presentaron a alguna licitación de cloaca pero no le daban las certificaciones y se les fue dando cosas chiquitas para que hicieran antecedentes. Porque para calificar en obras de cloaca y agua

75 "Brandinelli es el dueño único de Imepho, dueño de la florería del mismo nombre. Imepho se crea con Brandinelli y Muguetti, no el que estuvo con Russak sino el otro, Alejandro M ugueti, y el contador Elíades que cuando se muere le deja la herencia, esa famosa herencia y se crea la Compañía M arplatense de Construcción. Con Brandinelli crean esa Industria M arplatense Elaboradora de Productos de H ormigón. Después empezaron a trabajar en hormigón, y luego se metieron en obra pública" (entrevista con A. B.). Recuérdese también que en sus comienzos Nicolás Dazeo era albañil y se dedicaba al alquiler de caballos. 
había que tener un mínimo de puntaje para poder acceder, se requieren capacidad técnica y financiera. Son las dos capacidades que se requieren para eso" (entrevista con A. B.).

Concretamente, hay una relación de intercambio recíproco en la que a la empresa le significa la posibilidad de reproducción y acumulación económica y, al gobierno, acumulación de capital político (presente y/o futuro), y rehuir de un posible conflicto con el capital empresario local. Intercambio recíproco, lealtades y obediencias anticipadas, claro está, que implicaron costos sociales diferenciales a la sociedad que desplegaba otras estrategias en la apropiación del saneamiento.

La heterogeneidad empresarial materializada en el territorio expresa un conjunto de relaciones sociales que nos hablan de una ficción jurídica de igualdad en las licitaciones. Algunas de ellas refieren a:

- La permeabilidad gobierno-empresa:

El señor de la empresa es profesor de humanidades. M ilitante de los setenta, estudiaba filosofía en La Plata, estuvo viviendo en el sur, conoció a Kirchner. Con la democracia se hizo amigo nuestro. Un día suena el teléfono en el despacho de mi hermano y le dice "Che, vamos a hacer una obrita en MDP, estoy al frente de una empresa de mi suegro" [...]. Una semana antes que se abrieran los sobres, le digo: "Pero Daniel, abren los sobres la semana que viene y éste ya sabe que la ganó él" (entrevista a C. K., ex presidente de OSSE).

- La tercerización interempresarial:

No sé si estamos hablando de una gran corrupción, si realmente cobraba por cosas que no hacía, pero CoArCo era de agarrar cosas y "después veo cómo lo hago". Terciarizaba... (entrevista con A. B.).

- La asociación partido-empresa:

"CoArCo donde hay algo para hacer, siempre está. H ay una asociación muy directa entre radicalismo y CoArCo" (Ibidem).

- La asociación interempresarial:

"Entre CoArC o e Imepho creo que ha habido alguna asociación. En este mundo económico han sido aliados e inclusive socios, en algunas cosas" (Ibidem).

- La cartelización: 
Aparece Sanmartano y aparece CoArCo, en diferentes lugares; no todo el barrio tiene la misma empresa. Y es como que están adheridos porque el contrato se firmó con la otra empresa" (vecina del barrio San M artín).

Estas relaciones, que nuevamente hablan de la complementariedad y los difusos límites entre lo legal/ilegal, entre corrupción y colusión, han abierto los vínculos con los vecinos, quienes también desplegarán una multiplicidad de estrategias en defensa de sus condiciones de reproducción, resignificando constantemente esa identidad, al combinar en sus acciones distintas personificaciones.

La apócrifa escasez de recursos a la que aludía permanentemente oSSE imponía que "Las obras domiciliarias, las paga el que las usa. Las obras de saneamiento, de alguna manera, las tiene que pagar más de una generación" (Albino Bianchini, en reportaje televisivo).

Los mecanismos implementados para ello eran básicamente dos: el pago adelantado y el contrato vecino-empresa. El primero permitía alimentar el circuito financiero de oSSE y, el segundo, había derivado en un perverso instrumento expropiatorio.

O bras Sanitarias recauda, administra y ni siquiera controla las obras:

Q ue CoArCo cuando cotice, cotice más caro para compensar la gente que no paga [...] oSSE maneja esa plata, hace de control de esa plata, la privatiza teóricamente más barato y le asegura al CoArCo de turno que cuando presenta el certificado cobre (entrevista a O. P. jubilado de OSN). oSSE está cobrando la cuota, pero no son cañerías de oSSE" (vecino del barrio Villa Lourdes).

OSSE abrió la canilla. Lo más fácil [...]. Ellos dieron la factibilidad pero allá, en las oficinas [...]. Se hizo el zanjeo, el cruce, todo, todo como tenía que ser y todo lo hicieron los vecinos, pero el inspector nunca apareció (vecino del barrio Las Heras).

Así, los costos y conflictos se trasladan al barrio y las confrontaciones adquieren una dirección horizontal, además de vertical. Sin embargo, el barrio estaba fragmentado no sólo en sus estrategias de reclamos al gobierno, sino, sobre todo, hacia su interior, tensionado en varias dimensiones. La primera de ellas, como se recordará, es que el comienzo de las Avf como institución descansó en la fragmentación oficial del espacio y el poder como una respuesta del gobierno para legitimar una dominación y no como una necesidad vecinal. 
De esta manera, ambos campos, el político y el del barrio, están imaginariamente desarticulados pero en lo social anudados por la existencia de un mercado de influencias y de intercambios recíprocos de recursos. ${ }^{76}$

Precisamente, una segunda tensión es que lo que está en juego es una disputa en el tráfico de esas influencias, donde el principal recurso que se moviliza es el capital social, el cual, según las estrategias de reconversión, se transformará en capital político y/o en capital simbólico capaz de ejercer mayor influencia en el barrio y, por tanto, en la toma de decisiones respecto a la política urbana; es decir, nuevamente, en el destino de los recursos públicos.

$\mathrm{H}$ acia adentro, hay una estrategia de distanciarse de la política partidaria para mantener, hacia adentro, la relativa autonomía del campo barrial. Salirse de esta práctica podría poner en crisis la identidad del barrio. Empero, hacia afuera, la filiación partidaria de los fomentistas se utiliza dentro del campo político para incrementar los recursos materiales y simbólicos, personales y barriales. "Los vecinos del barrio Belgrano hicieron público a través de una nota su agradecimiento a la señora N orma G odoy y a la Gran Patriada Peronista" (La Capital, 15/03/1990). "Presidente y vice de la AVF Los Pinares agradecieron al senador provincial Saggese un subsidio" (La Capital, 29/06/1990).

Este doble juego es factible debido a las posibilidades de reconversión en capital político que porta el capital social del fomentista: "Vengo y encuentro que se han metido como 100 personas y resulta que está Pettigiani (un candidato a intendente) y le digo 'yo creía que el presidente de la entidad seguía siendo yo..." (C. D., fomentista).

A su vez, la contradicción del espacio generó al interior de los barrios una fragmentación socioespacial que es manipulada, tensionada, en un doble juego, delimitando, desplazando y construyendo identidades: 1) por los vecinos, reclamando obras que acorten las distancias materiales y simbólicas y 2) por los fomentistas, que reclaman una mejor distribución de los recursos públicos para desplazar una posible identidad imputada al barrio pero, también, emplazan a esa población por la falta de apoyo y participación, a la que le destinan los mayores esfuerzos: "Por suerte, $70 \%$ son propietarios que entienden la propuesta de avance [...]. $\mathrm{N}$ os falta la parte de arriba, pero estamos en eso [...] si no dicen que nos olvidamos de la gente de arriba" (entrevista a J. D., fo-

${ }^{76}$ Este acápite retoma y profundiza al gunas cuestiones planteadas en Lado y N úñez (2005). 
mentista). "Le pusimos mucho énfasis a ese lugar para que no se sientan discriminados" (entrevista a E. L., fomentista).

Pero ¿cuál es el lugar que ocupa la Avf en el barrio? Si bien más de $70 \%$ de la población ${ }^{77}$ conoce la existencia de la AVF, sólo $30 \%$ de los vecinos recurre a ella frente a al gún problema del barrio. ${ }^{78}$

Desde la mirada del vecino, las razones esgrimidas para no participar son "falta de tiempo", "porque nunca se resuelve nada", "por la conducción de la entidad" y "por que no le interesa participar". Pero, la pregunta sería: ¿por qué participar del juego instituido por otros? Esto torna casi inevitable que la renovación del mandato de la comisión directiva recaiga varios periodos en el mismo grupo, surgiendo así la figura del caudillo barrial: “Q uien me antecedió estuvo 10 años en esto de ser presidente [...] fuera de nosotros tres, es bastante jorobado encontrar quien quiera tomar alguna responsabilidad [....] colaborar" (entrevista a Juan Carlos Casado, presidente Avf La Florida).

Lo que queda claro es que una mayor participación produciría un mejor posicionamiento de los voceros del movimiento dentro del campo barrial, que le permitiría, a su vez (a partir de la visibilidad que le otorga el movimiento), traficar influencias en el campo político. Entonces, ¿quién y cómo construye la demanda? ¿Cómo se establece el juego entre vocero y representados? ¿Cómo se traduce este juego en la relación con el campo político y hacia adentro del campo barrial?

A veces, el vecino legítimo opera como intermediario entre el ocupante gratuito y oSSE y construye solidaridades, intercambiando capital económico por el trabajo del vecino pauperizado. En concreto:

${ }^{77}$ Con respecto a la muestra, se seleccionaron 15 áreas que se corresponden geográficamente con 15 aVf y 16 barrios (en el caso de la AVF Barrios Parque Montemar-EI Grosellar, una sola entidad vecinal representa dos barrios). El criterio respondió a un primer relevamiento, partiendo de las entrevistas realizadas a los fomentistas mencionados. La selección en esta primera etapa se hizo, asimismo, tratando de cubrir diferentes características. Se tomaron un total de 220 casos distribuidos de manera diferencial en las áreas relevadas, considerando las proporciones de género y edad, así como las proyecciones sobre el equilibrio poblacional del censo 2001 y la EPH-INDEC. En cada barrio se tomaron dos puntos muestras para captar la heterogeneidad intrabarrial. Para la selección de los casos en cada barrio, se decidió utilizar la técnica de búsqueda en espiral, partiendo de cada punto muestra (muestreo probabilístico por conglomerados estratificado por cuotas de sexo y edad, estableciendo un nivel de significación de $95.5 \%$ y un error calculado de un + - 5\% para el total de la muestra). El trabajo de campo se realizó en diciembre de 2003, en el marco de otro proyecto de investigación, bajo mi dirección.

${ }^{78}$ Estos resultados difieren según el barrio, toda vez que recurren en mayor porcentaje los vecinos de los barrios Parque del N orte, es decir, la mediana burguesía. 
- El vecino legítimo personifica la empresa, a la vez que articula acciones para la valoración económica y social del barrio. Es, también, un promotor: "OSSE aprobó el agua para las 24 manzanas del asentamiento del barrio Las Heras a condición de que los vecinos compraran todos los materiales necesarios y que hicieran las zanjas. Todo, to do, todo lo hizo el vecino [...]. El que no tenía, 'bueno, lo pongo yo, pero vos hacés toda la zanja' [...]. Era una manera de que todos tuvieran el agua" (vecina del barrio Las H eras).

O tras veces, la estrategia de cartelización de las empresas permite entablar negocios con el vecinalista, dando lugar a la colusión y desplazando a la institución política. Es decir,

- El vecino legítimo, dirigente barrial, puede ser corrupto y personificar a OSSE, eludiéndola: “Un día me reúno con vecinalistas: 'Vamos a empezar a hacer obras de cloaca y agua' [...]. H abían venido vecinalistas del norte. Les voy a contar esto y me van a hacer un monumento. ' $M$ iren, vamos a hacer obras' [...]. De todo me dijeron porque ahí había negocios [... no les gustó a los muchachos que la caja se las iba a manejar otro. Toneti mordía; Fernández Perona mordía y sigue mordiendo [...]. M al bicho. Ellos [las empresas] manejaban las obras vía la sociedad de fomento, entonces había mordidas. Sin ninguna duda" (entrevista con A. B.).

Esto lleva a profundizar la fractura vecinal debido a que los costos se inflan, llegando a la denuncia de otros vecinos, de la falsificación del contrato vecino-empresa, cuando no se reunía el acuerdo de $60 \%$ de los frentistas. En otros casos se induce al vecino moroso a que arregle con el abogado de la empresa constructora. Entonces,

- El vecino corrupto se transforma en persuasivo legítimo de aquellos a quienes introdujo en un conflicto legal ilegítimo, en función de sus intereses particulares, personificando la legalidad: "En el año 1999, 50\% de los vecinos del barrio debía las redes domiciliarias de agua a Sanmartano. Y estaban con juicio y a punto de remate entre 30 y $40 \%$ del barrio. De la sociedad de fomento se lo intima, se va a hablar: "Andá hasta el abogado y llevale \$20.00. Demostrale un poquito de interés'" (vecina del barrio San M artín). 
Claro está que otros vecinos están nutridos de valores diferentes:

- Los vecinos legítimos que, sin cuestionar la heteronomía, están apegados a lo instituido y a la moral de la palabra, como capital simbólico, personificando al peticionante obediente pasivo: "El único que dijo 'Le voy a tomar la palabra', un tal Benedetti, dice: 'Vamos a hacer la obra. H ace 30 años que estamos esperando la obra'. El de la Sociedad de Fomento Estrada. Una obra de cloaca. Esa es la que perdió CoArCo. Cuando se inauguró la obra, me dieron esta plaqueta 'En cumplimiento de la palabra'” (entrevista con A. B.).

Pero la construcción compleja de la heteronomía por medio de la palabra, de la promesa, crea

- El vecino capturado por el discurso del gobierno, que se lo apropia y reproduce, entrando en el juego del campo político-burocrático, aun en condiciones de máxima precariedad: "OSSE nunca nos dijo que no. Sólo hay que esperar los momentos y las oportunidades para realizarlo" (vecinos del barrio Belisario Roldán). "El agua es de pozo o clandestina, de hace 30 años. Cloacas, nada, todo pozo ciego. Recién se va a resolver cuando terminen la cuarta cloaca máxima" (vecinos del barrio Libertad). "La cloaca no va a venir hasta que no se termine la cuarta cloaca máxima [...]. Es lo que nos vendieron" (vecinos del barrio Santa Rosa de Lima).

En estos intercambios juega la imagen fetichizada del vecino de creer que pertenece, por un momento, al estado del poder. Es

- El vecino cooptado, personificando un inspector, ocupando el lugar de un técnico, desplazado a su vez, por el funcionario: "M arcelo López quiere que los vecinos participen y dice: 'Yo a mis empleados no les creo'. Entonces, directamente, tiene el número telefónico de los vecinos, que son los que inspeccionan a los inspectores. López es de los funcionarios que funcionan" (vecinos del barrio LoS Pinares).

La parte contraria es la fracción social que se opone a las obras, obstaculizando la urbanización pero, a la vez, alimentan- 
do el desarrollo de otras estrategias, apropiándose de la potencial renta diferencial y de la valoración económica y social del barrio, aportada por otros vecinos. N os referimos a

- El vecino ausente y el vecino terrateniente: "A Peralta Ramos todavía le quedan 300 lotes del bosque. N o paga, ¿no? Porque de 300 lotes no puede pagar. $\mathrm{H}$ ay quien paga y quien no paga [...]. El turista y el todavía terrateniente Aráoz, Peralta Ramos tiene en Santa Celina 300 y pico de lotes. Tiene que firmar por cada uno y no quiere endeudarse. Cuando los venda, los que vienen atrás, verán cómo lo pueden hacer" (entrevista a C. K., ex presidente de OSSE).

También la desocupación del otro, su estigmatización, se transforma en moneda de cambio que permite optimizar las propias estrategias de acumulación de capital económico. Es:

- El vecino legítimo que personifica la autoridad legítima, desplazando a las empresas constructoras: "Con el agua no nos metemos, pero con la cloaca no nos interesa que sea CoArCo o esas empresas. Q ue trabajen los desocupados del barrio" (vecina del barrio Jorge N ewbery).

Es que la crisis política, económica y social (una crisis orgánica, diría Gramsci), motivaba el surgimiento de nuevas estrategias vecinalistas. Frente a la desocupación, una de ellas consistió en formar parte de los cortes de ruta o piquetes, protestas implementadas alrededor de 1997, y liderados, en M ar del Plata, por dirigentes fomentistas: "Se cortaron las rutas para no dejar pasar el hambre y la desocupación a los barrios [...]. La necesidad del trabajador es ganarse el pan llevando el sueldo a su casa. Creo que en el trabajo está la dignidad de uno, de ganarse el pan uno mismo. La gente sin trabajo se desespera" ${ }^{79}$

La Comisión de Desocupados del Barrio Libertad, unida con la AVF para lograr mayor movilización en la comunidad, funciona desde 1995 y progresivamente fue ampliando la base de movilización. A partir de esta lucha organizada, los desocupados lograron llamar la atención del gobierno municipal y consiguieron que

${ }^{79}$ Entrevista a H éctor M aciel, dirigente del barrio Libertad, realizada por Effatá, año 1, 5, noviembre de 1997. La mayoría de los vecinos de este barrio trabajaba en el frigorífico San Telmo, el que redujo su planta de personal, en 1994, en $66 \%$. 
en la implementación del Plan Barrios ${ }^{80}$ se tuviera en cuenta a la Comisión de Desocupados de cada barrio y a las AVF: "Siempre le digo a M aciel, de Libertad: 'vos, cuando hagas un acto, no digas que sos fomentista, decí que sos de la clasista, hermano, porque me confundís a la gente' Si él recibe 4,000 pesos por mes del perro Santillán, y bueno, que diga que es de la corriente clasista y combativa" (entrevista a C. D., fomentista).

Contrario a esta estrategia, que intenta trascender su tradicional esfera de actuación articulándose, en todo el país, con el movimiento de desocupados y la corriente clasista y combativa, otros vecinalistas consideran que esta problemática es inherente a la esfera barrial:

La gente de la CD ideológicamente tiene una visión distorsionada de la realidad, entonces asignan al desocupado la imagen como que es un vago, es una lacra social, no trabaja porque no quiere, es un negro, ¿viste? Tiene ese concepto, no es que sean pobres sino que se abusan. Cuando se va a producir la renovación, los desocupados se empiezan a movilizar y empiezan a demandar que les permitan votar a todos. Entonces nosotros vimos que se intentaba desembarcar en la Avf no como herramienta para solucionar problemas del barrio, sino para solucionar problemas individuales o particulares (entrevista a E. L., fomentista).

Algunos dirigentes vecinales, basándose en la apuesta a la presidencia política, se apoyan en la negociación de otros integrantes de las comisiones directivas, preservando el rendimiento de su capital social en el barrio. 0 tros, aprovechando la posible reconversión de un capital en otro, decidieron entrar directamente al juego político y fracasaron, volviendo al campo barrial con menores posibilidades de renegociar influencias y viendo disminuir los recursos materiales para el barrio.

Este fracaso político de los dirigentes vecinales, además de demostrar los límites de reconversión de un capital en otro, refuerza las posibilidades de ejercicio de violencia simbólica y, por tanto, de reproducción del poder: "Los vecinos confían más en o SSE que en mecanismos de autogestión. Confían más en un organismo del Estado conducido por políticos, que en un procedi-

\footnotetext{
${ }^{80}$ Éste era un programa de trabajo por el cual los beneficiarios cobraban 200 pesos por mes (hoy Plan J efes y J efas de H ogar) y realizan trabajos propuestos por entidades de la comunidad o trabajos para la municipalidad. En el caso de las sociedades de fomento, éstas presentan un plan de trabajo barrial (reparación de pavimentos, plazas, forestación, veredas, etc.) y solicitan la inscripción de los vecinos del barrio o de barrios aledaños.
} 
miento autogestionario conducido por sus propios vecinos" (entrevista a C. K.).

Esto, a su vez, se justifica hacia dentro del campo barrial al mantener la creencia sobre la necesidad de prescindir de la política partidaria e imponiéndola como condición de la participación en el juego fomentista, reproduciendo, de esta manera, el discurso oficial y develando la función negada de las instituciones.

\section{A perturas para el cierre}

Este trabajo intenta constituir un aporte teórico-metodológico que contribuya al planteamiento de nuevas hipótesis de investigación. Partir de las relaciones sociales que se configuran y reconfiguran alrededor del agua, permitió problematizar conceptos cosificados y hegemónicos, para pasar a comprender prácticas, acciones y significaciones en relación con la política.

Así, desde la génesis urbana y de las fracciones sociales, que se fueron personificando de manera diferente, se fue haciendo presente ese "entramado de interdependencias constituido por individuos", en palabras de N orbert Elias, que luchan en función de sus distintos intereses y construyen/destruyen territorialidades sociales, estructurando relaciones de poder y un orden determinado, del que el espacio es coconstitutivo. Resignificar la territorialidad social como la imbricación de distintas espacialidades de pertenencia; una territorialidad que se construye, apropia y expropia permite superar aquellas perspectivas teóricas que, en los últimos años, han reducido la territorialidad a una sobrevaloración del barrio como ámbito social que pasó a cubrir funciones que las instituciones abandonaron (D el Cueto, 2008).

Por el contrario, abrir el barrio también como proceso, instrumento y resultado de lucha social, desnudó a los vecinos en distintas identidades, aun cuando todos ellos se enfrentan al problema del agua. Las personificaciones se trastocan y generan creencias que redefinen interacciones, vulneran relaciones sociales preexistentes y constituyen nuevas. En otras palabras, ejerciendo una violencia simbólica y naturalizada, en su vección horizontal y vertical y, por tanto, de reproducción del orden dominante.

Así, esa conjunción de promesas y creencias que construyen heteronomía e indefensión, conviven y se sostienen en el entrelazamiento de la estatalidad profunda y la estatalidad extensa, anclando las situaciones de dominio de una fracción social, sobre el conjunto. 
El Estado [...] es más bien un producto de la sociedad cuando llega a un grado de desarrollo determinado; es la confesión de que esa sociedad se ha enredado en una irremediable contradicción consigo misma y está dividida por antagonismos irreconciliables, que es impotente para conjurar [...]. Es exclusivamente el Estado de la clase dominante y, en todos los casos, una máquina esencialmente destinada a reprimir a la clase oprimida y explotada" (Engels, 2006: 183).

\section{Bibliografía}

Allen, Adriana, Julio Dávila y Pascale H ofmann (2005), “G obernabilidad y acceso al agua y saneamiento en la interfaz periurbana: análisis preliminar de cinco estudios de caso", Cuadernos del Cendes, año 22, 59, Caracas, pp. 23-44.

Ansaldi, Waldo (1992), "Frívola y casquivana; mano de hierro en guante de seda. Una propuesta para conceptuar el término oligarquía", en Patricia Funes (comp.), América Latina: planteos, problemas, preguntas, $M$ anuel Suárez Editor, Buenos Aires, pp. 13-20.

Ansaldi, Waldo (1997), "Fragmentados, excluidos, famélicos y, por si eso fuera poco, violentos y corruptos", Revista Paraguaya de Sociología, año 34, 98, Asunción, pp. 7-36. También disponible en http://www.catedras.fsoc.uba.ar/ udishal.

Bartolucci, M ónica (s/f), "La construcción. Una industria artesanal a principios de siglo en $\mathrm{M}$ ar del Plata. El nacimiento de un barrio en los relatos de sus actores", Grupo Historia Oral de $\mathrm{M}$ ar del Plata, informe de investigación, mimeo.

Borges, Antonádia (2006), "O emprego na política e suas implicações teóricas para uma antropologia da política", em Anuario Antropológico/2005, Tempo Brasileiro, Río de Janeiro, pp. 91-125.

Bourdieu, Pierre (1996), “Espíritu de Estado. Génesis y estructura del campo burocrático", Sociedad, 8, UBA, Buenos Aires, pp. 5-29. 
Bourdieu, Pierre (1993), Cosas dichas, Gedisa, Barcelona.

Bourdieu, Pierre y Loïc Wacquant (1995), Respuestas para una antropología reflexiva, Grijalbo, M éxico.

Brunstein, Fernando (1989), Agua potable en el Gran Buenos Aires: un drama popular, CEAL, Buenos Aires.

Castells, M anuel (1988), Crisis urbana, Estado y participación popular, Colegio de Arquitectos de Bolivia, Cochabamba.

Castro, Esteban (1999), "El retorno del ciudadano: Ios inestables territorios de la ciudadanía en América Latina", Perfiles Latinoamericanos, 14, FLACso, M éxico, pp. 39-62.

Colombo, Eduardo (1993), “La integración imaginaria del proletariado", en Eduardo Colombo (comp.), El imaginario social, Piedra Libre 3-N ordan, M ontevideo, pp. 171-182.

Comisión Pro M ar del Plata (1921), Memoria. Presentada a la asamblea de vecinos y veraneantes cel ebrada el día 27 de febrero de 1921, Talleres Gráficos L. J. Rosso, Buenos Aires.

Cova, Roberto (1981), "H istoria de la arquitectura de $\mathrm{M}$ ar del Plata, 1857-1938", Arquitectura, Asociación de Arquitectos de $\mathrm{M}$ ar del Plata, $\mathrm{M}$ ar del Plata, pp. 14-30.

Cueto, Carla del (2008), "Territorio y sectores populares. Una discusión entre la geografía y la sociología", Prácticas de O ficio. Investigación y Reflexión en Ciencias Sociales, un GsIDES, 1, Buenos Aires, pp. 11-18.

Elias, N orbert (1982), Sociología fundamental, Gedisa, Barcelona.

Engels, Federico (2006), El origen de la familia, la propiedad privada y el Estado, www.marxist.org/espanol/m-e/1880s/origen/index.htm.

Espinosa Saldaña, Eloy (1997): "Apuntes sobre las dificultades existentes para la protección de los derechos sociales en el modelo de jurisdicción constitucional español", en Ger- 
mán Bidart Campos (comp.), Economía, constitución y derechos sociales, EDIAR, Buenos Aires, pp. 199-240.

Funes, Patricia (1992), "Pensando América Latina en la década del '20: una generación entre el Edipo y el parricidio", en Patricia Funes (comp.), América Latina: planteos, problemas, preguntas, M anuel Suárez Editor, Buenos Aires, pp. 101-116.

Foucault, M ichel (1992), Microfísica del poder, La Piqueta, M adrid.

Gandolfi, Fernando (1996), "O bras públicas, islas artificiales y aeropuertos. Entre la historia y la fantasía", I + A, año 2, 4, UNM DP, M ar del Plata, pp. 65-92.

Giordano, Verónica (2002), “Q ué va cha ché. La corrupción en Argentina es un problema de la democracia", Ágora. Revista de Ciencias Sociales, 7, Centre d'Etudis Politics i Socials, Valencia, pp. 197-219. También disponible en http://www.catedras.fsoc.uba.ar/udishal.

Gutiérrez, Alicia (2004), Pobre, como siempre... Estrategias de reproducción social en la pobreza, Ferreyra, Córdoba, Argentina.

H olloway, J ohn (1994), Marxismo, Estado y capital. La crisis como expresión del poder del trabajo, Fichas temáticas de Cuadernos del Sur, Tierra del Fuego.

Izaguirre, Inés y Zulema A ristizábal (2002): “Las luchas obreras 1973-1976. Los alineamientos de la clase obrera durante el gobierno peronista. N uevas consideraciones teóricometodológicas para el estudio de los conflictos obreros", Instituto de Investigaciones Gino Germani-Facultad de Ciencias Sociales-Universidad de Buenos Aires, Buenos Aires, http://www.iigg.fsoc.uba.ar/Publicaciones/DT/.

Kowarick, Lucio (1991), “Ciudad y ciudadanía. Análisis de metrópolis del subdesarrollo industrializado", Nueva Sociedad, 114, Caracas, pp. 84-93. 
Kreutzer, G. U. (1953), "Servicios sanitarios en el Segundo Plan Q uinquenal", Revista de osN, año xvII, 153, Buenos Aires, pp. 200-208.

Lado, Silvana y Ana N úñez (2005), “Identidad espacio-temporal vecinal y violencia simbólica", en Jorge Roze, Susana M urillo y Ana N úñez (comps.), N uevas identidades urbanas en América Latina, Espacios, Buenos Aires, pp. 15-34.

Lenin, Vladimir (2004), ¿Q ué hacer?, N uestra América, Buenos Aires.

Lourau, René (1980), El Estado y el inconsciente. Ensayo de sociología política, Kairos, Barcelona.

Lourau, René (2001), El análisis institucional, Amorrortu, Buenos Aires, mimeo.

M arín, Juan Carlos (s/f), Cuadernos, serie Teoría, Buenos Aires, mimeo.

M arín, Juan Carlos (1993), “El no-delito: ¿tan sólo una ilusión?", Delito y Sociedad, año II, 3, Buenos Aires, pp. 133-152.

M arín, Juan Carlos (1996), Conversaciones sobre el poder (una experiencia colectiva), Instituto Gino Germani-CBC-UBA, Buenos Aires.

M arín, Juan Carlos (1984), Acerca del origen del poder. Ruptura y propiedad, cicso, Buenos Aires.

M arín, Juan Carlos (2003), Los hechos armados. Argentina, 19731976, La Rosa Blindada-P.I.CA.so, Buenos Aires.

M arques, Eduardo (2000), Estado e redes sociais: permeabilidade e coesão nas políticas urbanas no Rio de Janeiro, FAPESPRevan, Río de Janeiro.

M arques, Eduardo (2003), Redes sociais, instituições e atores políticos no governo da cidade de São Paulo, FAPESP-Annablume, San Pablo, Brasil. 
M arques, Eduardo y Renata Bichir (2001), "Estado e espaço urbano: revisitando críticamente as explicações sobre as políticas urbanas", Revista de Sociologia e Política, 16, Curitiba, pp. 9-28.

M arx, Carlos (1968), Crítica de la filosofía del Estado de H egel, Grijalbo, M éxico.

M arx, Carlos (1965), El Capital, Cartago, Buenos Aires.

M arx, Carlos y Federico Engels (1848), El Manifiesto Comunista, http://www.laeditorialvirtual.com.ar/Pages/M arx/.

M urillo, Susana, Ignacio Amatrain, Dana Borzese, Julia Coria, N atalia Gianatelli, Laura Guardia, M atías Landau, Vanesa Luro, Roberta Ruiz, Paula Santamaría, Patricia Terranova, Eva Vazquez (2005), "Buenos Aires, entre el miedo a las epidemias y la angustia frente al riesgo", en J orge Roze, Susana M urillo y Ana Núñez (comps.) N uevas identidades urbanas en América latina, Espacios, Buenos Aires, pp. 117-160.

N úñez, Ana (2000), Morfología social. Mar del Plata, 1874-1990, Grafikart, Tandil.

N úñez, Ana (2006), “Lo que el agua (no) se llevó. Política urbana, Estado del poder, violencia, e identidades sociales. $M$ ar del Plata, entre siglos", tesis doctoral, FLACSO, http:/ www.flacso/publicaciones.php.

N úñez, Ana (2007), “Entre gallos y medianoche, nos municipalizaron. Expropiación y reapropiación del territorio de O bras Sanitarias de la N ación (Argentina), Trabajo y sociedad, Ix (9), Universidad N acional de Santiago del Estero, pp. 1-37, disponible en http://www.unse.edu.ar/trabajoysociedad/

N úñez, Ana (2008), "H ay una cosa que se llama M ar del Plata, donde está $M$ artín. Sobre la génesis urbana y las fracciones sociales", en Nómadas. Revista Crítica de Ciencias Sociales y Jurídicas, 1 (17), Universidad Complutense de M adrid, http://www.ucm.es/info/nomadas/. 
Pastoriza, Elisa (1993), Los trabajadores de Mar del Plata en vísperas del peronismo, CEAL, Buenos Aires.

Pereira, X avier (1986), “Valorização imobiliária, movimentos sociais e espoliação", Sinopses, 9, fauusp, São Paulo, pp. 205-232.

Pereira, X avier (2005), “D inâmica imobiliária e metropolizaçao: a nova lógica do crescimento urbano em São Paulo", texto presentado en el VII Coloquio Internacional de Geocrítica, Santiago de Chile

Pérez de la Vega, Javier (2004), El crecimiento económico no resuelve la pobreza, Forum, Barcelona.

Rebón, Julián (2004), Desobedeciendo al desempleo. La experiencia de las empresas recuperadas, P.I.CA.So-La Rosa Blindada, Buenos Aires.

Revista del Centro de Jubilados y Pensionados M unicipales Marplatenses (2005), año 7, 25, M ar del Plata.

Rovani, Yves (1979), “El problema de abastecimiento de agua y de eliminación de residuos", Finanzas y Desarrollo, 16 (1), Fondo M onetario Internacional-Banco M undial, Washington, pp. 14-18.

Roze, Jorge, Ana Pratesi, M aría Andrea Benítez, y Lidia M obilio (1999), Trabajo, moral y disciplina en los chicos de la caIle, Espacio Editorial, Buenos Aires.

Roze, Jorge (2003), Inundaciones recurrentes. Ríos que crecen, identidades que emergen, Al M argen, La Plata.

SN AP (Servicio N acional de Agua Potable) (1968), "Plan N acional de Agua Potable", AIDIS, Ingeniería Sanitaria, xI Congreso Interamericano de Ingeniería Sanitaria, Quito.

Weber, M ax (1992), Economía y sociedad, Fondo de Cultura Económica, Buenos Aires. 
Woollands, H éctor (1990), Reseña histórica del barrio Florencio Sánchez, Sociedad de Fomento Florencio Sánchez, M ar del Plata.

Woollands, H éctor (1999), Recuerdos de un militante anarquista, El M artillo, M ar del Plata

Z uppa, G raciela (1997), "Plazas: lecturas de huellas y registros", en F. Cacopardo (ed.), Mar del Plata. Ciudad e historia, apuestas entre dos horizontes, Alianza, Buenos Aires, pp. 201-240.

Recibido: 14 de marzo de 2008. Aceptado: 29 de agosto de 2008.

A na N úñez. Es doctora en ciencias sociales por flacso. Asimismo, es arquitecta por la Universidad $\mathrm{N}$ acional de $\mathrm{M}$ ar del Plata y maestra en ciencias sociales por fLAcso. Actualmente es investigadora nivel $\|$ en el SIN y directora del Centro de Estudios del D esarrollo Urbano de la Universidad $\mathrm{N}$ acional de $\mathrm{M}$ ar del Plata, y del Grupo de Investigación en Socioantropología Urbana. Su línea de investigación actual es el análisis relacional de los conflictos por la apropiación del espacio y los servicios básicos, imbricados en la conceptualización de apropiación/expropiación de territorialidades sociales. Entre sus últimas publicaciones destacan: "Política urbana y proceso de estatalidad", Confluências. Revista interdisciplinar de sociología e direito, 1 (9), Universidad Federal Fluminense, Brasil, pp. 97-126 (2007); "Los linderos perdidos de la política urbana: estado del poder, violencia e identidades sociales", en E. O rtecho, P. Peyloubet y L. de Salvo (comps.), Ciencia y tecnología para el hábitat popular. Construcción y participación del conocimiento, Nobuko, Buenos Aires, pp. 261-272 (2007); Campo político, campo barrial. ¿(Di)visiones en pugna?, Suárez, M ar del Plata (2007); "H ay una cosa que se Ilama $M$ ar del Plata, donde vive M artín. Sobre la génesis urbana y las fracciones sociales", N ómadas. Revista Crítica de Ciencias Sociales y Jurídicas, 1 (17), Universidad Complutense de M adrid, pp. 241-254 (2008). 